Article

\title{
Assessment of Merged Satellite Precipitation Datasets in Monitoring Meteorological Drought over Pakistan
}

\author{
Khalil Ur Rahman ${ }^{1}\left(\mathbb{D}\right.$, Songhao Shang ${ }^{1, *} \mathbb{D}$ and Muhammad Zohaib ${ }^{2}(\mathbb{D}$ \\ 1 State Key Laboratory of Hydroscience and Engineering, Department of Hydraulic Engineering, \\ Tsinghua University, Beijing 100084, China; hlrhm17@tsinghua.org.cn \\ 2 Graduate School of Water Resources, Sungkyunkwan University, Suwon 440-746, Korea; zohaib557@skku.edu \\ * Correspondence: shangsh@tsinghua.edu.cn; Tel.: +86-10-6279-6674
}

Citation: Rahman, K.U.; Shang, S.; Zohaib, M. Assessment of Merged Satellite Precipitation Datasets in Monitoring Meteorological Drought over Pakistan. Remote Sens. 2021, 13, 1662. https://doi.org/10.3390/ rs13091662

Academic Editor: Ali Behrangi

Received: 17 March 2021

Accepted: 21 April 2021

Published: 24 April 2021

Publisher's Note: MDPI stays neutral with regard to jurisdictional claims in published maps and institutional affiliations.

Copyright: (c) 2021 by the authors. Licensee MDPI, Basel, Switzerland. This article is an open access article distributed under the terms and conditions of the Creative Commons Attribution (CC BY) license (https:// creativecommons.org/licenses/by/ $4.0 /$ )
Abstract: The current study evaluates the potential of merged satellite precipitation datasets (MSPDs) against rain gauges (RGs) and satellite precipitation datasets (SPDs) in monitoring meteorological drought over Pakistan during 2000-2015. MSPDs evaluated in the current study include Regional Weighted Average Least Square (RWALS), Weighted Average Least Square (WALS), Dynamic Clustered Bayesian model Averaging (DCBA), and Dynamic Bayesian Model Averaging (DBMA) algorithms, while the set of SPDs is Global Precipitation Measurement (GPM)-based Integrated MultiSatellite Retrievals for GPM (IMERG-V06), Tropical Rainfall Measurement Mission (TRMM) MultiSatellite Precipitation Analysis (TMPA 3B42 V7), Precipitation Estimation from Remotely Sensed Information using Artificial Neural Networks (PERSIANN), and ERA-Interim (re-analyses dataset). Several standardized precipitation indices (SPIs), including SPI-1, SPI-3, and SPI-12, are used to evaluate the performances of RGs, SPDs, and MSPDs across Pakistan as well as on a regional scale. The Mann-Kendall (MK) test is used to assess the trend of meteorological drought across different climate regions of Pakistan using these SPI indices. Results revealed higher performance of MSPDs than SPDs when compared against RGs for SPI estimates. The seasonal evaluation of SPIs from RGs, MSPDs, and SPDs in a representative drought year (2008) revealed mildly to moderate wetness in monsoon season while mild to moderate drought in winter season across Pakistan. However, the drought severity ranges from mild to severe drought in different years across different climate regions. MAPD (mean absolute percentage difference) shows high accuracy (MAPD < 10\%) for RWALS-MSPD, good accuracy $(10 \%<$ MAPD < 20\%) for WALS-MSPD and DCBA-MSPD, while good to reasonable accuracy $(20 \%<$ MAPD $<50 \%)$ for DCBA in different climate regions. Furthermore, MSPDs show a consistent drought trend as compared with RGs, while SPDs show poor performance. Overall, this study demonstrated significantly improved performance of MSPDs in monitoring the meteorological drought.

Keywords: meteorological drought; standardized precipitation index; satellite precipitation datasets; merged precipitation datasets; complex topography

\section{Introduction}

Population growth and their improving standard of living, increase in agricultural and industrial production, water quality deterioration, and several other factors influence and intensify our freshwater needs across the global and regional scales [1]. Moreover, the infelicitous spatial and temporal distributions of water resources result in water scarcity in different regions at different times. Therefore, appropriate water management and planning policies become an arduous task to implement in several regions and results in potential conflicts between various stakeholders [2]. This problem becomes a devastating issue during the drought season when there are serious climate change implications on water security, environmental sustainability, and socio-economic developments. Climate change is anticipated to augment the duration, frequency, and intensity (severity) of droughts and 
other hydro-climatic extremes [1]. The arid (hyper-arid and semi-arid) regions are more prone to climate change mitigation, where the precipitation and soil moisture availability is already very low.

Droughts are the most catastrophic natural phenomena, which adversely impact the livelihoods, including vegetation and livestock, and other natural resources, i.e., water, biodiversity, and ecology [3-7]. Drought significantly depends on the changing climate and spatiotemporal variation of precipitation and has a profound impact on the water resources and agriculture of a region. Droughts are often originated from precipitation deficit and can end up with enormous socio-economic and agricultural losses $[8,9]$. The primary reason for any drought is the deficiency in precipitation (such that it causes soil moisture deficit and water stress) for particulate time, distribution, and intensity in relation to existing water storage, availability, and demand [10]. Droughts are directly connected with water availability; hence, climate change will have a profound impact on water scarcity and food security [11]. Droughts are categorized into three major types, including meteorological, hydrological, and agricultural droughts, based on duration, intensity, impact, and recovery rate [12].

The impact of drought is even more severe in developing countries such as Pakistan, which is one of the most vulnerable countries to drought because of its dependence on agriculture. Moreover, Pakistan is significantly affected by climate change, and the increase in temperature complemented by variability in precipitation will cause more intense and prolonged droughts events [13]. Several drought events have occurred in recent years across different parts of the world, especially in the Balochistan province of Pakistan in 1997-2003 (hyper-arid regions in the current study) [14]. Therefore, drought estimation is extremely important for countries such as Pakistan to mitigate the impacts of droughts on water resources and agriculture sectors.

Precipitation plays a vital role in drought monitoring and water resources management [15-17]. Therefore, reliable and precise estimation of precipitation is extremely important for hydrologic modeling [18] and drought indices estimation to enumerate drought conditions [19]. Drought is aggravated continuously at a global and regional scale under the influence of global warming and climate change [20-22], which leads to devastating economic and ecological losses across the globe $[17,23,24]$.

The in situ precipitation records from rain gauges (RGs) are the traditional method and provide more accurate point-scale observations [15]. However, the RGs are often non-uniformly and sparsely distributed, more specifically over complex terrain and various environmental conditions in developing countries and regions $[25,26]$. Due to the uneven and sparse distribution of RGs augmented with a high level of uncertainties and spatial variability of precipitation, RGs often prevent the estimation of actual soil moisture conditions $[15,27,28]$. Therefore, the insufficiency of RGs for monitoring droughts has been addressed in a number of studies $[20,29,30]$, which is emphasizing on application and development of continuous precipitation datasets for drought assessment [19].

The advancement in remote sensing and retrieval algorithms provided alternative precipitation data sources, i.e., satellite precipitation products (SPDs), which addressed most of the errors and problems associated with RG observations [18,31]. SPDs provide continuous precipitation records and capture the spatiotemporal variability of precipitation at regional and global scales with latitude bands up to $60^{\circ} \mathrm{NS}$ [32,33]. SPDs usually retrieve the precipitation information from infrared (IR), passive microwave (PMW), or space-borne precipitation radars (PR) [34]. The most widely used SPDs are Tropical Rainfall Measurement Mission (TRMM) Multi-Satellite Precipitation Analysis (TMPA) [32], Global Precipitation Measurement (GPM) mission [35], Precipitation Estimation from Remotely Sensed Information using Artificial Neural Networks (PERSIANN) [36,37], Climate Prediction Center Morphing (CMORPH) [38], and ERA-Interim [39]. However, the individual SPD exhibits significant inevitable errors and biases in precipitation estimates.

Several efforts have been made to improve and reduce the errors in SPDs precipitation estimates, i.e., improving the retrieval and calibration algorithms, reduce sampling 
problems, application of adaptive and relative weights, merging of more than two SPDs using dynamic weights [40-42]. Several merged SPDs (MSPDs) are developed across various regions of the globe and especially in Pakistan. Very recently, machine learning (ML) techniques have become popular in hydrological modeling, climate studies, water resources management [43,44], and precipitation sciences [45-47]. Different ML techniques have also been employed for merging different SPDs and SPDs with RGs. For example, Zhang et al. [48] merged multiple SPDs and RGs using double machine learning (DML) across mainland China. The performance of DML is also compared with standalone ML techniques, including random forest (RF), extreme machine learning (EML), artificial neural network (ANN), and support vector machine (SVM). Results reported dominant performance of DML as compared with RF, EML, ANN, SVM, gauge-only interpolated, and merging SPDs. Bhuiyan et al. [49] developed MSPD using quantile regression forest (QRF) over tropical regions of the Iberian Peninsula. Baez-Villanueva et al. [50] used RF ML to merge SPDs with RGs across Chile. Wehbe et al. [51] used ANN to develop MSPD by merging weather radar, SPDs, and RGs. Wu et al. [52] developed MSPD using SPDs and RGs by employing a spatiotemporal deep fusion (SDF) algorithm over China. Yin et al. [53] developed MSPD using the cuckoo search (CS) algorithm and BMA at threestages over China. Results demonstrated better performance of three-stage MSPD than individual SPDs.

Very few studies are available that developed MSPDs over the complex topography of Pakistan characterized by diverse climate. The developed MSPDs across Pakistan include Dynamic Bayesian Model Averaging (DBMA-MSPD) [54], Dynamic Clustered Bayesian Model Averaging (DCBA-MSPD) [18], Dynamic Weighted Average Least Square (WALSMSPD) [55], and Regional Dynamic Weighted Average Least Square (RWALS-MSPD) [56]. The results reported that MSPDs have significant improvements in precipitation estimates and higher potential for hydrological applications [57,58].

Currently, the major challenge in the application of SPDs for monitoring drought is the low accuracy of SPDs, which is associated with the calibration of SPDs against RGs, sampling issues, and disturbance due to other radiation sources [27]. Various studies have assessed the performance and accuracy of SPDs to monitor drought $[16,17,26,59-64]$. These studies reported that the SPDs performance showed a high dependency on local climate, topographic complexity, and the density of RGs used for bias correction. Moreover, the finding also revealed that SPDs have poor performance in arid/hyper-arid climate regions with a severe environment than other climate regions $[60,64,65]$. However, the MSPDs showed higher potential for hydrological applications $[57,58]$ and will be worthy of monitoring drought over the data-scarce regions.

Therefore, objectives of the current study are twofold: (i) to assess the potential of MSPDs (DCBA-MSPD, DBMA-MSPD, WALS-MSPD, and RWALS-MSPD) to monitor drought, (ii) to evaluate the performance of MSPDs against the RGs and SPDs over Pakistan. Moreover, Mann-Kendall (MK) test is also performed to investigate the trend of drought across different climate regions of Pakistan. The performance of MSPDs and SPDs are also evaluated on a regional scale by dividing Pakistan into four climate regions, including glacial, humid, arid, and hyper-arid regions. Pakistan has a limited number of RGs that do not meet scientific and management requirements [25]. Searching for the best alternative precipitation sources and assessing their potential applications are of utmost importance for Pakistan. Therefore, evaluating the potential of SPDs and MSPDs across Pakistan will help researchers and water resources managers to know their potential strengths and limitations in drought monitoring.

\section{Materials and Methods}

\subsection{Study Area}

Pakistan is geographically situated in western South Asia between $23.5^{\circ}$ and $37.5^{\circ} \mathrm{N}$ and longitude $62^{\circ}$ to $75^{\circ} \mathrm{E}$ and covers an area of $803,940 \mathrm{~km}^{2}$ (Figure 1a). The elevation of Pakistan ranges from $8600 \mathrm{~m}$ at Hindukush-Himalaya $(\mathrm{HKH})$ mountain ranges situated 
in the extreme north to $0 \mathrm{~m}$ at the coast of the Arabian Sea located at extreme south $[41,66]$. Pakistan shares its boundaries with China (north), Afghanistan (west), Iran (west), and India (east) [18,67]. Pakistan has a very diverse climate ranging from glacial to humid, arid, and hyper-arid regions with extreme north to south trends. According to climate variability, the study area is divided into glacial, humid, arid, and hyper-arid regions (Figure 1b).

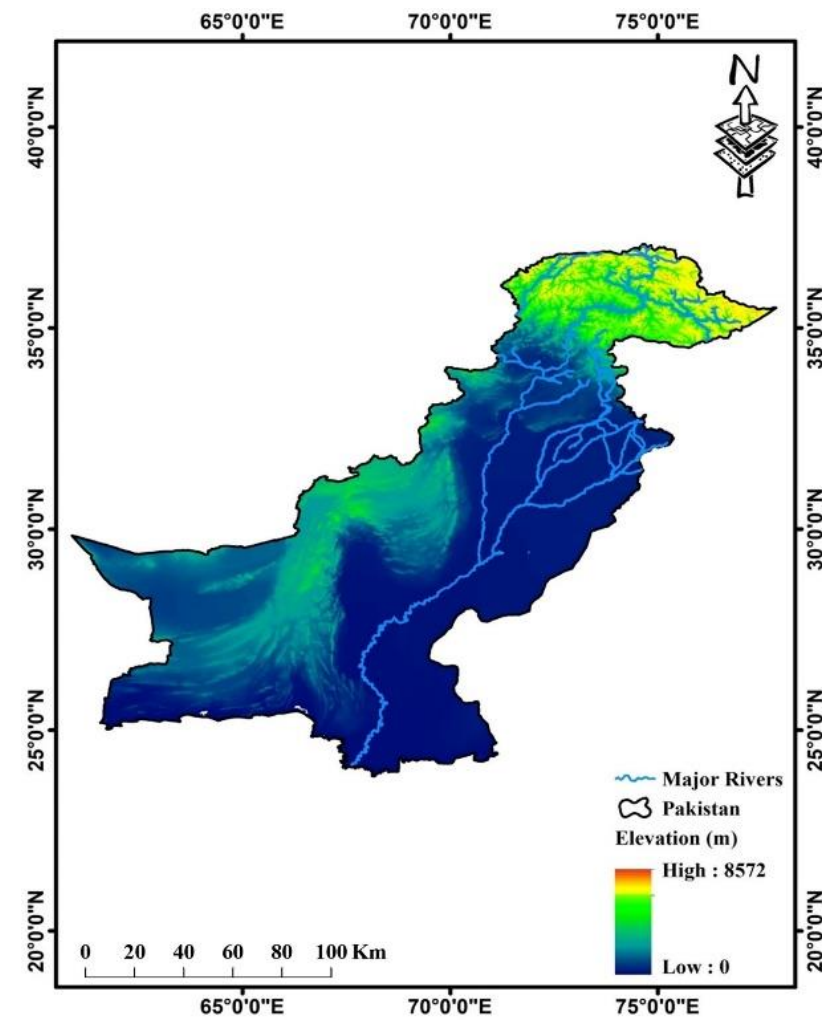

(a)

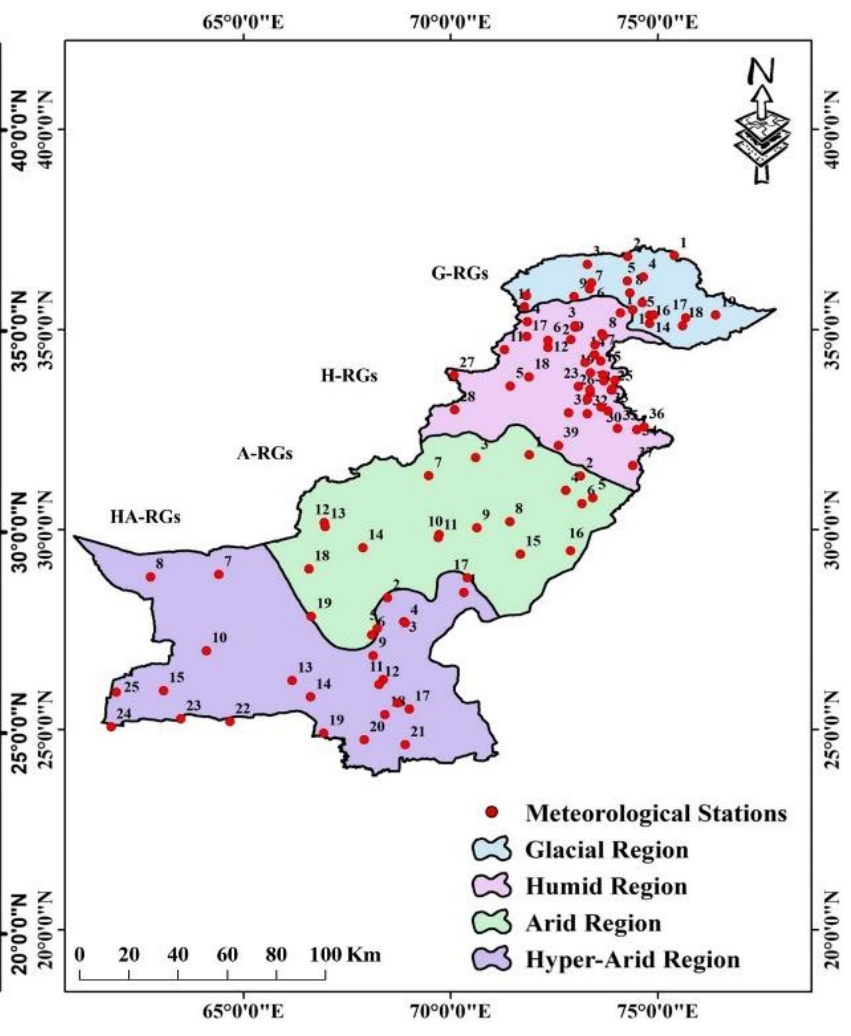

(b)

Figure 1. Study area and geographical distribution of meteorological stations (RGs). (a) Elevation map retrieved from Shuttle Radar Topography Model (SRTM), and (b) Climate regions considered in the current study.

The glacial region is situated between $34^{\circ} \mathrm{N}$ and $38^{\circ} \mathrm{N}$ and comprises permanent snow and glacier cover with mean elevation and mean annual precipitation of $4158 \mathrm{~m}$ and $348 \mathrm{~mm}$, respectively. The famous HKH mountain ranges are situated in glacial zone where the snowmelt of HKH during the summer season provides the sustainable source of water in the Indus River and its tributaries [54]. The water from snowmelt supports the domestic, agricultural, and industrial water needs of Pakistan. On the other hand, excessive snowmelt also causes devastating flood events, e.g., flood in 2010 [25]. According to Köppen-Geiger climatic regions classification, glacial region is comprised of a polar, cold climate with dry summer and arid nature.

The average elevation and mean annual precipitation of humid region is $1286 \mathrm{~m}$ and $852 \mathrm{~mm}$, respectively. Almost all the major rivers of Pakistan, including the Indus River and its tributaries, including Swat, Kabul, Hunza, Panjkora, Gilgit, Chitral, Jhelum, and Kurram, are originating from the humid region. The humid region is the hydraulically developed region of Pakistan, and it consists of the largest dams, including Tarbela and Mangla dams, which are constructed on Indus and Jhelum rivers with installed hydropower capacities of 3500 MW and 1000 MW, respectively [68]. The Köppen-Geiger classification for the humid region includes temperate to cold climate (arid in extreme south), dry to no dry seasons, and warm/hot summer.

Arid region is the agricultural hub (Punjab province) of Pakistan, characterized by average elevation and mean annual precipitation of $633 \mathrm{~m}$ and $322 \mathrm{~mm}$, respectively [69]. 
Indus and Jhelum river with their tributaries, are the sustainable water resources supporting not only the agriculture but also industrial and domestic sectors [18]. The plain areas in arid region are having a dry and hot climate and are comprised of the famous Thar Desert. The mildly elevated mountains situated in the west of the arid region exhibit the cold climate (during December and January) and hot summer [70]. The Köppen-Geiger classification shows that plain areas of arid region are of typically arid nature with hot climate and desert regions. However, the classification for mountainous areas (extreme west) ranges from arid nature with a cold climate characterized by dry and hot summer.

Sindh and some parts of the Balochistan provinces of Pakistan are situated in the hyper-arid region (extreme south). The average elevation and mean annual precipitation of the hyper-arid region are $444 \mathrm{~m}$ and $133 \mathrm{~mm}$, respectively. The hyper-arid region comprises deserts, plateaus, barren lands, dry mountains, and coastal regions along the Arabian Sea [54]. The Köppen-Geiger classification shows that hyper-arid region has an arid climate with hot summer and mostly comprised of deserts.

There are four seasons in Pakistan distinguished on the basis of temperature (precipitation): cold and dry winter during December to March (winter season), hot and dry spring during April to June (pre-monsoon season), hot and humid summer during July to September (monsoon season), and dry autumn during October to November (post-monsoon season) [54,71]. Pakistan receives heavy and moderate precipitation during monsoon (due to Indian monsoon season) and winter (due to western disturbance), respectively. Indian monsoon originates from the Bay of Bengal and enters Pakistan from its east and northeast sides [25]. It is a source of precipitation in central, eastern, and southern Pakistan [72]. However, the western disturbances originate from Caspian, Mediterranean, and Black Seas that enter Pakistan from the west and southwest sides [73] and are the sources of precipitation over the west and east regions of Pakistan. In addition to these seasons, there are two cropping seasons in Pakistan, i.e., Kharif and Rabi. The Kharif season (May-October) and Rabi season (November-April) are experienced during Indian monsoon and western disturbances, respectively [8]. These cropping seasons are extremely important to agriculture from the economic point of view of Pakistan [74].

Precipitation is highly erratic over Pakistan and consistent with variation in climate. Monsoon is the dominant season during which Pakistan receives 55\% to $60 \%$ of the total annual precipitation [75]. The general precipitation pattern during the intense precipitation season (monsoon) is given as follows: low magnitude $(<100 \mathrm{~mm})$ in the north (glacial region), high magnitude $(>700 \mathrm{~mm})$ in the humid region, and again low magnitude $(<100 \mathrm{~mm})$ in the hyper-arid region [41]. Moderate precipitation accounting for about 30\% of total annual precipitation occurs in the winter season. The humid region (Figure 1b) receives the highest amount of annual precipitation $(>1500 \mathrm{~mm})$, while less than or around $100 \mathrm{~mm}$ of precipitation occurs in the hyper-arid region in the south.

\subsection{In Situ Precipitation Data}

Precipitation data at 102 RGs have been collected from the Pakistan Meteorological Department (PMD) and Water and Power Development Authority (WAPDA) for the period of 2000-2015. WAPDA collects the precipitation data under Snow and Ice Hydrology Project (SIHP), which mostly operates at high elevations located in glacial and humid regions [18]. Out of the collected 102 RGs, precipitation records from 79 RGs are obtained from PMD, while the rest were from WAPDA. Figure $1 \mathrm{~b}$ shows the geographical location and distribution of RGs in each climate region. In the current research, the RGs are named according to the climate regions where they are situated, i.e., RGs in glacial, humid, arid, and hyper-arid regions are designated as G-RGs, H-RGs, A-RGs, and HA-RGs, respectively.

PMD and WAPDA manually collect most of the precipitation records of RGs that might be subjected to several types of errors. Moreover, the RGs at high altitude might be subjected to a number of external factors such as splashing and wind errors, which affect the data quality. Therefore, PMD and WAPDA follow the World Meteorological Organization standard code (WMO-N) to evaluate and rectify the RG precipitation records. 
Moreover, to ensure high-quality data, the quality tests, including skewness and kurtosis, were performed on the collected RG data. The missing data were filled by employing the zero-order method following Rahman et al. [41].

\subsection{Satellite Precipitation and Merged Satellite Precipitation Datasets (SPDs/MSPDs)}

Four SPDs and four MSPDs are considered in the current study. The considered SPDs are the final version of Global Precipitation Measurement (GPM)-based Integrated MultiSatellite Retrievals for GPM (IMERG-V06) [76], TMPA 3B42V7 [32], and PERSIANN-CDR [37], and a re-analysis dataset ERA-Interim [39]. The MSPDs include DBMA-MSPD [54], DCBAMSPD [18], WALS-MSPD [55], and RWALS-MSPD [56]. Note that post-real time versions of SPDs have been used to develop the MSPDs.

RWALS-MSPD is developed using several conventional (top-down) SPDs, including IMERG V06, TMPA 3B42V7, PERSIANN-CDR, and ERA-Interim, and soil moisture-based precipitation datasets (bottom-up), i.e., SM2RAIN-ASCAT [77,78] and SM2RAIN-CCI [79,80]. RWALS-MSPD is developed by employing the WALS algorithm [44], which merges the SPDs based on their spatial assessment and selection of appropriate SPDs for a particular climate region. The top-down and bottom-up SPDs are developed using different algorithms and behave differently across all the climate regions of Pakistan [25]. Therefore, the inclusion of bottom-up SPDs abated the high magnitude of uncertainties across glacial and humid regions, and they presented significantly improved results. The precipitation data for SM2RAIN-ASCAT are available from 2007 to 2018; therefore, weights for all the SPDs are calculated from 2007 to 2015. Then, the weights are extrapolated from 2016 to 2018 using the Auto-Regressive Integrated Moving Average (ARIMA) model. It is worth mentioning that all the above-mentioned MSPDs are developed by dynamically varying the weights of individual SPDs using pixel-to-pixel analyses. Readers are referred to Rahman et al. $[18,43]$ for the detailed description of the dynamic variation of SPDs weights.

Table 1 lists the information, including temporal and spatial resolutions, and retrieval/developing algorithms, related to SPDs and MSPDs. Before the assessment of drought using the SPDs and MSPDs, it is ensured that all the datasets have similar spatial resolution covering the same period. Therefore, the IMERG SPD is resampled to $0.25^{\circ}$ from $0.1^{\circ}$ spatial resolution. RWALS-MSPD has a different temporal span as compared with previously developed MSPDs, which is due to the inclusion of SM2RAIN-ASCAT dataset available after the year 2007 [25,78].

Table 2 list the different combination of SPDs used to develop the MSPDs. It should be noted that a similar set of SPDs is used to develop DBMA-, DCBA-, and WALS-MSPDs. However, due to the considerable magnitude of errors in glacial and humid regions, several SPDs are tested across each climate region, and the best SPDs are selected to develop RWALS-MSPD. As compared to other MSPDs, RWALS-MSPD is developed using several conventional (top-down) SPDs, including IMERG V06, TMPA 3B42V7, PERSIANN-CDR, and ERA-Interim (re-analyses precipitation dataset), and soil moisture-based precipitation datasets (bottom-up), i.e., SM2RAIN-ASCAT and SM2RAIN-CCI. RWALS-MSPD is developed using different combinations of SPDs for each climate region. Initially, all SPDs are evaluated in each climate region using MAD and correlation coefficient $(R)$. The SPDs performed best are selected to developed RWALS-MSPD for that particular region. Readers are referred to Rahman and Shang [56] for detailed information about RWALS-MSPD. 
Table 1. Description of SPDs and MSPDs used for monitoring drought.

\begin{tabular}{|c|c|c|c|c|c|}
\hline SPD/MSPD & $\begin{array}{c}\text { Spatial } \\
\text { Resolution }\end{array}$ & $\begin{array}{l}\text { Temporal } \\
\text { Span }\end{array}$ & $\begin{array}{l}\text { Temporal } \\
\text { Resolution }\end{array}$ & $\begin{array}{l}\text { Retrieval/Merging } \\
\text { Algorithm }\end{array}$ & References \\
\hline IMERG V06 & $0.10^{\circ}$ & $2000-2015$ & 1-day & $\begin{array}{l}\text { Goddard profiling algorithm } \\
\text { GPCC monthly gauge }\end{array}$ & [76] \\
\hline TMPA 3B42 V7 & $0.25^{\circ}$ & 2000-2015 & 1-day & $\begin{array}{c}\text { observation to correct the bias } \\
\text { of 3B42RT }\end{array}$ & [32] \\
\hline Era-Interim & $0.25^{\circ}$ & 2000-2015 & 1-day & 4D-Var analysis & [39] \\
\hline PERSIANN-CDR & $0.25^{\circ}$ & 2000-2015 & 1-day & $\begin{array}{c}\text { Adaptive artificial neural } \\
\text { network }\end{array}$ & [37] \\
\hline DBMA-MSPD & $0.25^{\circ}$ & 2000-2015 & 1-day & $\begin{array}{c}\text { Dynamic Bayesian Model } \\
\text { Averaging (DBMA) }\end{array}$ & {$[54]$} \\
\hline DCBA-MSPD & $0.25^{\circ}$ & 2000-2015 & 1-day & $\begin{array}{c}\text { Dynamic Clustered Bayesian } \\
\text { Model Averaging (DCBA) }\end{array}$ & [18] \\
\hline WALS-MSPD & $0.25^{\circ}$ & 2000-2015 & 1-day & $\begin{array}{l}\text { Dynamic Weighted Average } \\
\text { Least Square (WALS) }\end{array}$ & [55] \\
\hline RWALS-MSP & $0.25^{\circ}$ & 2007-2018 & 1-day & $\begin{array}{c}\text { Dynamic Regional Weighted } \\
\text { Average Least Square (RWALS) }\end{array}$ & [56] \\
\hline
\end{tabular}

Table 2. Combination of different SPDs used to develop the MPDs over Pakistan.

\begin{tabular}{cccccc}
\hline \multirow{2}{*}{ MSPDs } & No. & \multicolumn{3}{c}{ Climate Regions } \\
\cline { 3 - 6 } & 1 & Glacial & Humid & Arid & Hyper-Arid \\
\cline { 2 - 5 } RWALS & 2 & IMERG V06 & IMERG V06 & IMERG V06 & IMERG V06 \\
& 3 & TMPA 3B42 V7 & TMPA 3B42 V7 & TMPA 3B42 V7 & SM2RIAN-ASCAT \\
& 4 & SM2RAIN-ASCAT & SM2RAIN-ASCAT & SM2RAIN-ASCAT & SM2RAIN-CCI \\
WALS & $1-4$ & PERSIANN-CDR & SM2RAIN-CCI & SM2RAIN-CCI & Era-Interim \\
DCBA & $1-4$ & \multicolumn{2}{c}{ TMPA 3B42 V7, PERSIANN-CDR, ERA-Interim, and CMORPH } \\
DBMA & $1-4$ & \multicolumn{2}{c}{ TMPA 3B42 V7, PERSIANN-CDR, ERA-Interim, and CMORPH } \\
\hline
\end{tabular}

\subsection{Methods}

Flowchart (as shown in Figure 2) summarizes the method employed to assess the potential of MSPDs and SPDs to monitor meteorological drought across different climate regions of Pakistan.

The preliminary steps include the division of Pakistan into different climate regions based on regional climate and precipitation magnitude and the selection of precipitation input datasets (RGs, MSPDs, and SPDs). In the next step, SPI-3 is selected to illustrate the spatial distribution of drought across Pakistan during monsoon and winter seasons at all RGs shown in Figure 1. For the sake of parity, the precipitation data from SPDs and MSPDs (which is available in the form of a $0.25 \mathrm{deg}$ grid) is extracted against the RGs. Then, the SPIs time series for SPDs and MSPDs are calculated at grid having at least one RG across each climate region, while SPI values are averaged at grids having more than one RG. Thus, it is ensured that RGs, SPDs, and MSPDs have the same temporal spans (except for RWALS-MSPD) and have the same spatial attributes. Furthermore, SPI-1, SPI-3, and SPI-12 are used to demonstrate the time-series of drought across all climate regions at the representative RGs (stations). A representative RG (RRGs) is the RG having similar precipitation magnitude, drought pattern, and drought intensity as compared to most of the RGs in a particular climate region. The time series of drought is calculated for all RGs in each climate region and then compared with each other. The comparison revealed that most RGs have a similar pattern of time series drought in each climate region. Therefore, the RRGs selected by Rahman et al. [18] are considered as RRGs in the current study. Moreover, the pixels opposite to RRGs are considered as representative pixels (RPs, of SPDs and MSPDs) for the regional time series drought assessment. The climate division of Pakistan is performed such that each climate region has almost similar characteristics, i.e., similar magnitude, 
intensity, and frequency of precipitation, climate, etc. Furthermore, the Taylor diagram is used to show the spatial variability of drought in each climate region, and the diagrams did not show any significant variation in drought estimates. Therefore, RRGs and RPs (across each climate region) represent the time series of regional drought of each climate region and are used to graphically represent the distribution pattern of drought (time-series) across each climate region.

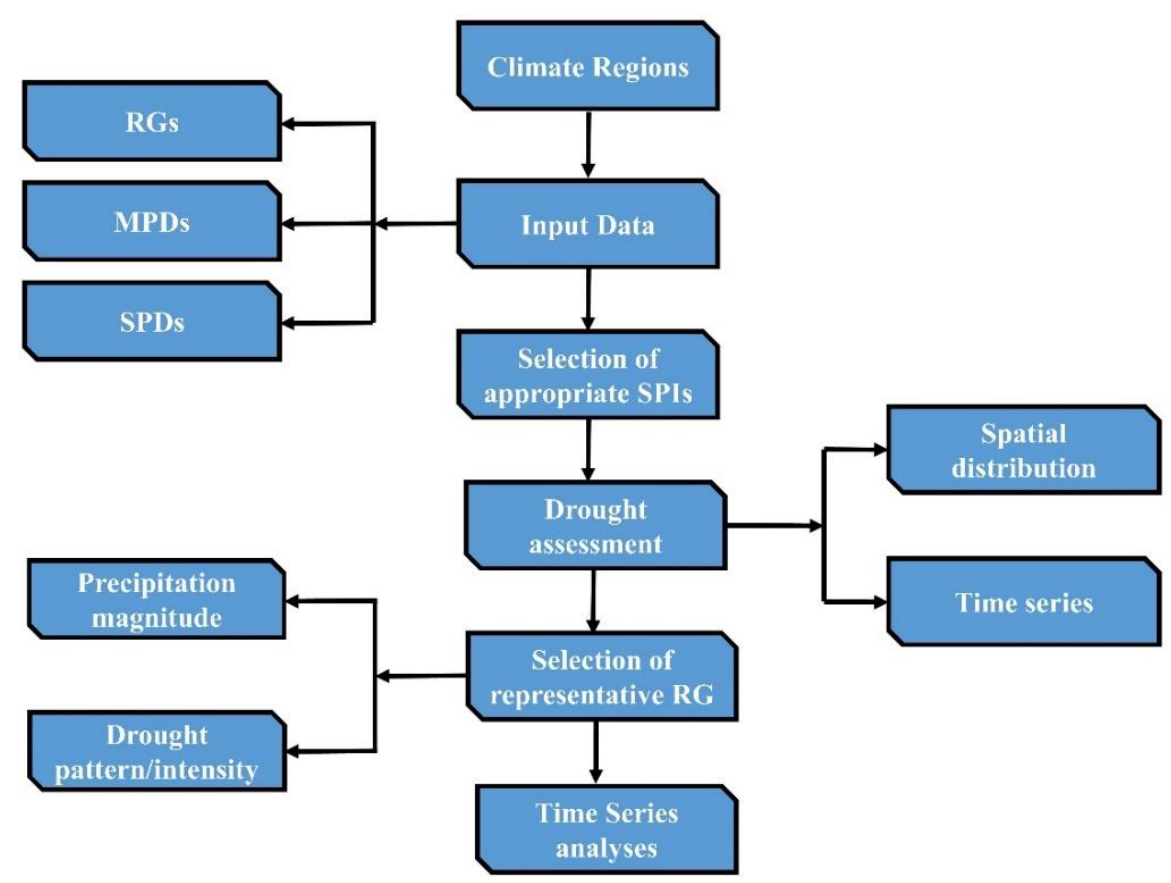

Figure 2. Flowchart of the proposed methodology.

\subsubsection{Standardized Precipitation Index (SPI)}

The SPI is the most widely used drought index for monitoring meteorological drought. It is defined as the standardized departure of the variable (precipitation) from its climatological mean. For precipitation, the deficit is estimated based on monthly data aggregates at various time scales (in this study, 1, 3, and 12 months are considered). For example, a 3-month SPI is calculated by summing up precipitation from month $j-2$ to month $j$, and the value is assigned to month j; thus, the first two months of SPI data are not available. In the next step, a standardization process begins in which a suitable probability density function is fitted to the long-term time series of accumulated precipitation. Then, the function fitted is used to calculate the cumulative distribution of data points, which are eventually converted to normal standard variates. Similarly, this procedure is replicated for other time scales. Conventionally, the SPI is derived by fitting gamma distribution to the data; however, Farahmand and AghaKouchak [81] reported that wrong distribution fitting causes erroneous drought demonstrations mainly due to tail-related errors in the distribution function. Keeping in view this limitation, Farahmand and AghaKouchak [81] introduced a non-parametric standardized analysis toolbar (SDAT) to calculate meteorological, agricultural, and hydrological drought using the following equations:

$$
F\left(y_{j}\right)=\frac{j-0.44}{k+0.12}
$$


where $k$ is the sample size, $j$ is the rank of non-zero precipitation data points in ascending order, and $F\left(y_{j}\right)$ is the empirical probability at month $j$. Then, the Standardized Precipitation Index (SPI) can be approximated from

$$
\begin{gathered}
\mathrm{SPI}=\left\{\begin{array}{l}
-\left(t-\frac{c_{0}+c_{1} t+c_{2} t^{2}}{1+d_{1} t+d_{2} t^{2}+d_{d^{3}} t^{3}}\right), 0<F(y) \leq 0.5 \\
+\left(t-\frac{c_{0}+c_{1} t+c_{2} t^{2}}{1+d_{1} t+d_{2} t^{2}+d_{3} t^{3}}\right), 0.5<F(y) \leq 1
\end{array}\right. \\
t=\sqrt{\ln \left(\frac{1}{(F(y))^{2}}\right)}, 0<F(y) \leq 0.5 \\
t=\sqrt{\ln \left(\frac{1}{1-(F(y))^{2}}\right)}, 0.5<F(y) \leq 1
\end{gathered}
$$

where $c_{0}=2.212217, c_{1}=0.802853, c_{2}=0.010328, d_{1}=1.432788, d_{2}=0.189269$, and $d_{3}=0.001308$ are constants.

SPI indices for spatial representation are calculated for every RG (102 in total) across each climate region, where the daily precipitation data are accumulated to monthly precipitation. The SPIs are calculated for all grids ( 0.25 degrees) across all climate regions of Pakistan. However, for the sake of parity, the SPDs and MSPDs pixels containing a single RG are used to compare the performance of SPDs and MSPDs against RGs. In the case of pixels containing more than one RG, the SPI for each RG is averaged for that particular pixel. Then, the calculated SPIs for RGs are interpolated over the entirety of Pakistan using the ordinary kriging $(\mathrm{OK})$ method.

In the current study, SPI-1, SPI-3, and SPI-12 are selected to assess the drought on spatial and temporal (during four seasons) scales across Pakistan. SPI-1, SPI-3, and SPI-12 are used to depict the short-term (monthly), medium (seasonal), and long-term (annual) drought on the regional scale.

SPI has many advantages over other drought indices, e.g., it depends only on precipitation and can be used for both dry and rainy seasons, and it is flexible and can be calculated for multiple time scales. The probabilistic nature of SPI offers a historical context that is ideal for decision making and thus well adapted for decision making. It can describe drought conditions that are important for a range of meteorological, agricultural, and hydrological applications. Table 3 is used to determine the consistency of drought intensity and duration and to spatially distribute the drought over Pakistan.

Table 3. Standard SPI Table [82].

\begin{tabular}{cc}
\hline SPI Range & Description \\
\hline$>2$ & Extremely wet \\
1.5 to 1.99 & Very wet \\
1.0 to 1.49 & Moderately wet \\
0 to 1.0 & Mildly wet \\
-1.0 to 0 & Mildly drought \\
-1.5 to -1.0 & Moderately drought \\
-2.0 to -1.5 & Severe drought \\
$<-2$ & Extreme drought \\
\hline
\end{tabular}

\subsubsection{Mann-Kendall (MK) Test}

The Mann-Kendall (MK) test, a non-parametric test for trend detection, was proposed and developed by Mann (1945) and Kendall $[83,84]$. The MK test is extensively used for trend analyses and has the capability to handle non-normal and censoring data with high efficiency [85]. The MK test is used in this study to detect the drought trend over different climate regions. The null hypothesis $\left(\mathrm{H}_{0}\right)$ for the MK test in the current study is that there is no significant trend in drought (SPI 1,3, and 12) over time, while the alternative 
hypothesis $\left(\mathrm{H}_{1}\right)$ is that there is a significant trend (either increasing or decreasing) over time. The mathematical expression for MK test is given below:

$$
\begin{gathered}
\text { MK }=\sum_{i=1}^{n-1} \sum_{j=i+1}^{n} \operatorname{sign}\left(x_{j}-x_{i}\right) \\
\operatorname{sign}\left(x_{j}-x_{i}\right)=\left\{\begin{array}{cl}
+1 & , \text { if }\left(x_{j}-x_{i}\right)>0 \\
0 & , \text { if }\left(x_{j}-x_{i}\right)=0 \\
-1 & , \text { if }\left(x_{j}-x_{i}\right)<0
\end{array}\right. \\
V(\mathrm{MK})=\frac{1}{18}\left[n(n-1)(2 n+5)-\sum_{p=1}^{q} t_{p}\left(2 t_{p}-1\right)\left(2 t_{p}+5\right)\right] \\
S=\left\{\begin{array}{c}
\frac{\mathrm{MK}-1}{\sqrt{V(\mathrm{MK})}}, \mathrm{MK}>0 \\
0, \mathrm{MK}=0 \\
\frac{\mathrm{MK}+1}{\sqrt{V(\mathrm{MK})}}, \mathrm{MK}<0
\end{array}\right.
\end{gathered}
$$

where $V(\mathrm{MK})$ and $S$ represent the variance and standardized MK test statistics. The $x_{i}$ and $x_{j}$ are the time-series observations of drought indices in chronological order, $n$ is the total number of observations in a time series data, $t_{p}$ represents the number of ties of $p$ th values, and $q$ is the number of tied values. Positive values of " $S$ " denote the positive trend, while negative values represent the negative trends. $\mathrm{H}_{0}$ is rejected in a case when $|S|>Z_{1-\alpha / 2}$ describing the statistically significant trend in drought indices at a significance level of $\alpha$, where $Z_{1-\alpha / 2}$ denotes the 100(1- $\left./ 2\right)$-th percentile of the standard normal distribution.

\subsubsection{Sen's Slope}

Sen's slope is used to estimate the trends in drought indices time series, which is a non-parametric test proposed by Sen [86]. Sen's slope $(Q)$ is mathematically represented using the following equations:

$$
\begin{gathered}
Q=\operatorname{median}\left(S S_{i j}\right) \\
S S_{i j}=\frac{x_{j}-x_{i}}{j-i}, 1 \leq I<j \leq n
\end{gathered}
$$

where $x_{j}$ and $x_{i}$ represent drought indices at time $j$ and $i(1 \leq i<j \leq n)$, respectively, $S S_{i j}$ is the linear slope between time $i$ and $j$, and $Q$ is the median of $S S_{i j}(1 \leq i<j \leq n)$. Positive and negative $Q$ values depict the increasing and decreasing trends of drought indices over time, respectively.

\subsubsection{Performance Evaluation of SPDs and MSPDs against the RGs in Drought Monitoring}

The performance of SPDs and MSPDs are evaluated against the RGs (considered as a reference) in drought monitoring using three statistical indices, including Mean Absolute Difference (MAD), Root Mean Square Difference (RMSD), and Mean Absolute Percentage Difference (MAPD) [87]. The minimum values of MAD, RMSD, and MAPD depict an accurate estimation of drought by SPDs/MSPDs. According to Lewis [88], MAPD less than 10 represents high accurate estimation, good estimation is depicted by MAPD ranging between 10 and 20, MAPD ranging from 20 to 50 represents reasonable estimation, while higher than 50 shows inaccurate estimates. The equations for these indices are given below:

$$
\begin{aligned}
\text { MAD } & =\frac{1}{N} \sum_{t=1}^{N}\left|O_{t}-E_{t}\right| \\
\text { RMSD } & =\sqrt{\frac{1}{N} \sum_{t=1}^{N}\left(O_{t}-E_{t}\right)^{2}}
\end{aligned}
$$




$$
\mathrm{MAPD}=\frac{1}{N} \sum_{t=1}^{N}\left|\frac{\left(O_{t}-E_{t}\right)}{O_{t}}\right| \times 100
$$

where $O_{t}$ and $E_{t}$ are RGs-based, and SPDs/MSPDs-based estimated drought indices, respectively, $N$ is the total number of observations, and the subscript " $t$ " in MAPD represents the time period.

\section{Results}

Several studies have reported the topographic, time scale, climatic, elevation, and seasonal dependencies of SPDs, which are propagated to the developed MSPDs [18,89]. However, despite these dependencies and uncertainties associated with SPDs, MSPDs have a high potential for hydrological applications [57]. Therefore, the current study evaluates the performances of SPDs and MSPDs in drought assessment, considering RGs as a reference. The obtained results are comprehensively explained in the following sub-sections: Section 3.1 presents the performance assessment of MSPDs and SPDs to monitor drought for a representative drought year using SPI-3, Section 3.2 presents the regional scale evaluation of SPDs and MSPDs for drought monitoring, and Section 3.3 shows trend analyses of drought in different climate regions of Pakistan.

\subsection{Performance of MSPDs and SPDs in Drought Assessment for a Representative Drought Year}

Since the focus of the current study is to evaluate the performance of MSPDs and SPDs in monitoring meteorological drought, the year with minimum precipitation is selected for spatial representation of drought over Pakistan. The procedure to select the suitable drought year includes calculation of average precipitation (2000-2015) at each RG and the selection of potential drought years that have precipitation less than the estimated average precipitation (at each $\mathrm{RG}$ ). There were several years whose precipitation was less than average precipitation, but 2000, 2001, 2003, 2007, 2008, and 2012 were the common years at most RGs. However, based on the availability of precipitation data from all the datasets (to data for RWALS-MSPD before 2007), the year 2008 is selected for the spatial distribution of seasonal drought indices.

Figure 3 shows the spatial distribution of SPI-3-based drought severity during monsoon season across different climate regions of Pakistan. Drought severity in Figure 3 is categorized based on the division recommended by McKee et al. [71], as shown in Table 3. Figure 3 shows mildly wet conditions for RGs, MSPDs, and SPDs (only IMERG and TMPA). The average SPI-3 values for RGs, RWALS, WALS, DCBA, DBMA, IMERG, and TMPA across Pakistan are $0.38,0.47,0.55,0.64,0.77,0.89$, and 0.98 , respectively. On the other hand, moderate wetness is observed for PERSIANN-CDR and ERA-Interim with average SPI-3 values of 1.09 and 1.16 .

The drought assessment on a regional scale shows that RGs, RWALS, and WALS have presented mildly wet conditions; DCBA, DBMA, IMERG, and TMPA depicted moderate wet conditions; while PERSIANN-CDR and ERA-Interim presented very wet conditions in the glacial region. The average regional SPI-3 values for RGs, RWALS, WALS, DCBA, DBMA, IMERG, TMPA, PERSIANN-CDR, and ERA-Interim are 0.68, 0.80, 0.95, 1.04, 1.17, $1.32,1.40,1.58$, and 1.73 , respectively. However, all precipitation datasets presented mildly wet to moderate wet conditions in the humid region except for the PERSIANN-CDR and ERA-Interim, which show moderate to very wet conditions. The regional average SPI-3 ranges from a minimum of 0.64 (RGs) to a maximum of 1.32 (Era-Interim).

Arid and hyper-arid regions show both drought and wet conditions; therefore, the average SPI-3 values in both regions demonstrate mildly wet conditions across both regions. The maximum wet and drought conditions in arid region are observed at A-RG12 and A-RG17 with RGs-based SPI-3 values of 0.96 and -0.78 , respectively. The regional average SPI-3 values of RGs, RWALS, WALS, DCBA, DBMA, IMERG, TMPA, PERSIANN-CDR, and ERA-Interim are 0.16, 0.22, 0.27, 0.34, 0.41, 0.53, 0.60, 0.71, and 0.77, respectively. Similarly, the maximum drought and wet conditions in hyper-arid regions are observed at HARG6 and HA-RG24 with RG-based SPI-3 values of -0.68 and 0.55 . The regional average SPI-3 
values of RGs, RWALS, WALS, DCBA, DBMA, IMERG, TMPA, PERSIANN-CDR, and ERAInterim are $-0.07,-0.11,-0.15,-0.20,-0.26,-0.32,-0.35,-0.47$, and -0.42 , respectively.
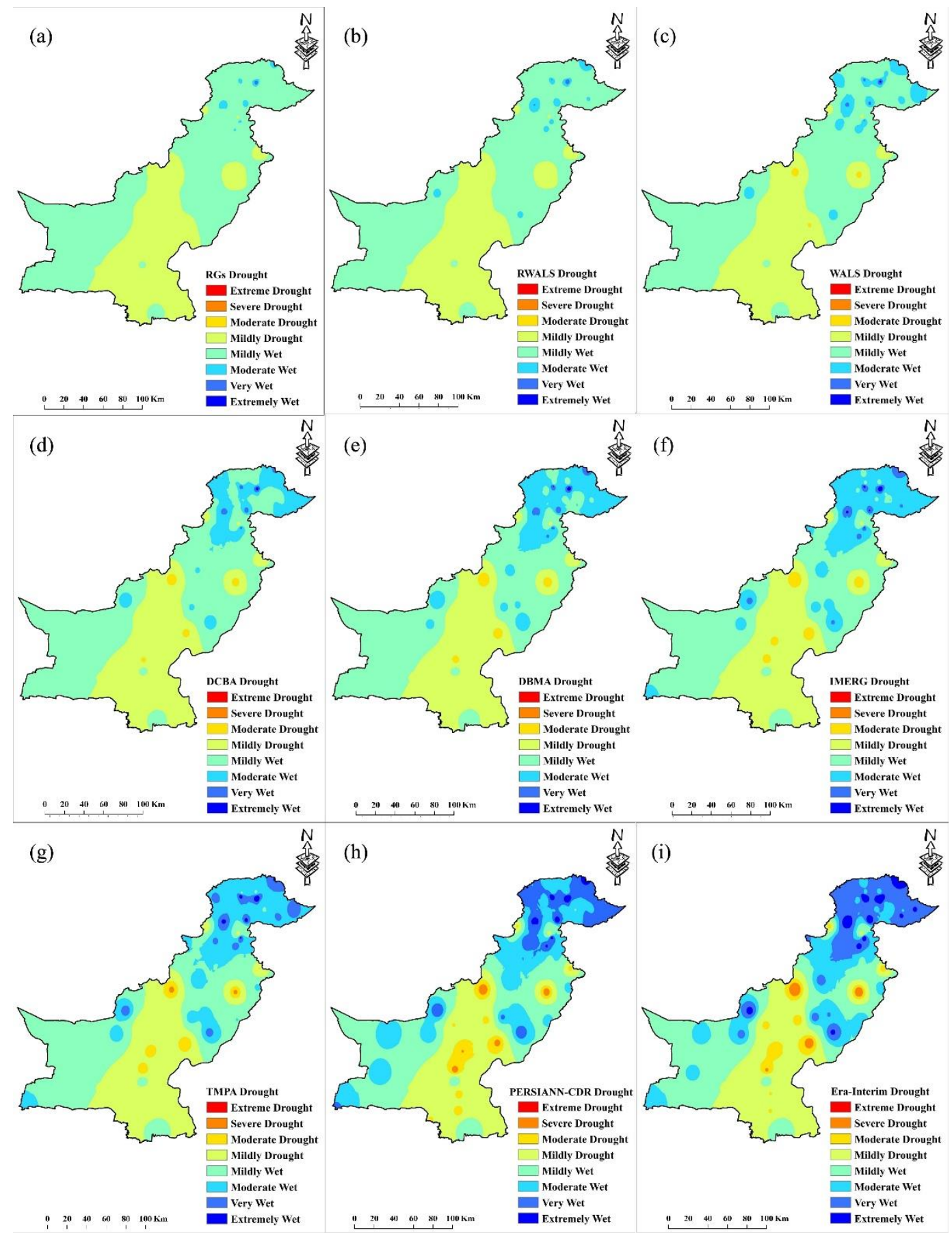

Figure 3. Spatial distribution of drought index (SPI-3) across Pakistan during the monsoon season in the representative drought year (2008), (a) RGs, (b) RWALS-MSPD, (c) WALS-MSPD, (d) DCBA-MSPD, (e) DBMA-MSPD, (f) IMERG, (g) TMPA, (h) PERSIANN-CDR, and (i) ERA-Interim.

The winter season shows mild to moderate drought across different climate regions of Pakistan (Figure 4). The intensity of drought is increasing from RGs and MSPDs toward the ERA-Interim. RGs and MSPDs except for the DCBA and DBMA (only at a few RGs) show mild to moderate drought, which amplifies to severe drought for individual SPDs across Pakistan. The average SPI-3 values for RGs, RWALS, WALS, DCBA, DBMA, IMERG, 
TMPA, PERSIANN-CDR, and ERA-Interim overall Pakistan are $-0.84,-0.90,-0.97,-1.08$,

$-1.21,-1.39,-1.47,-1.63$, and -1.78 , respectively.
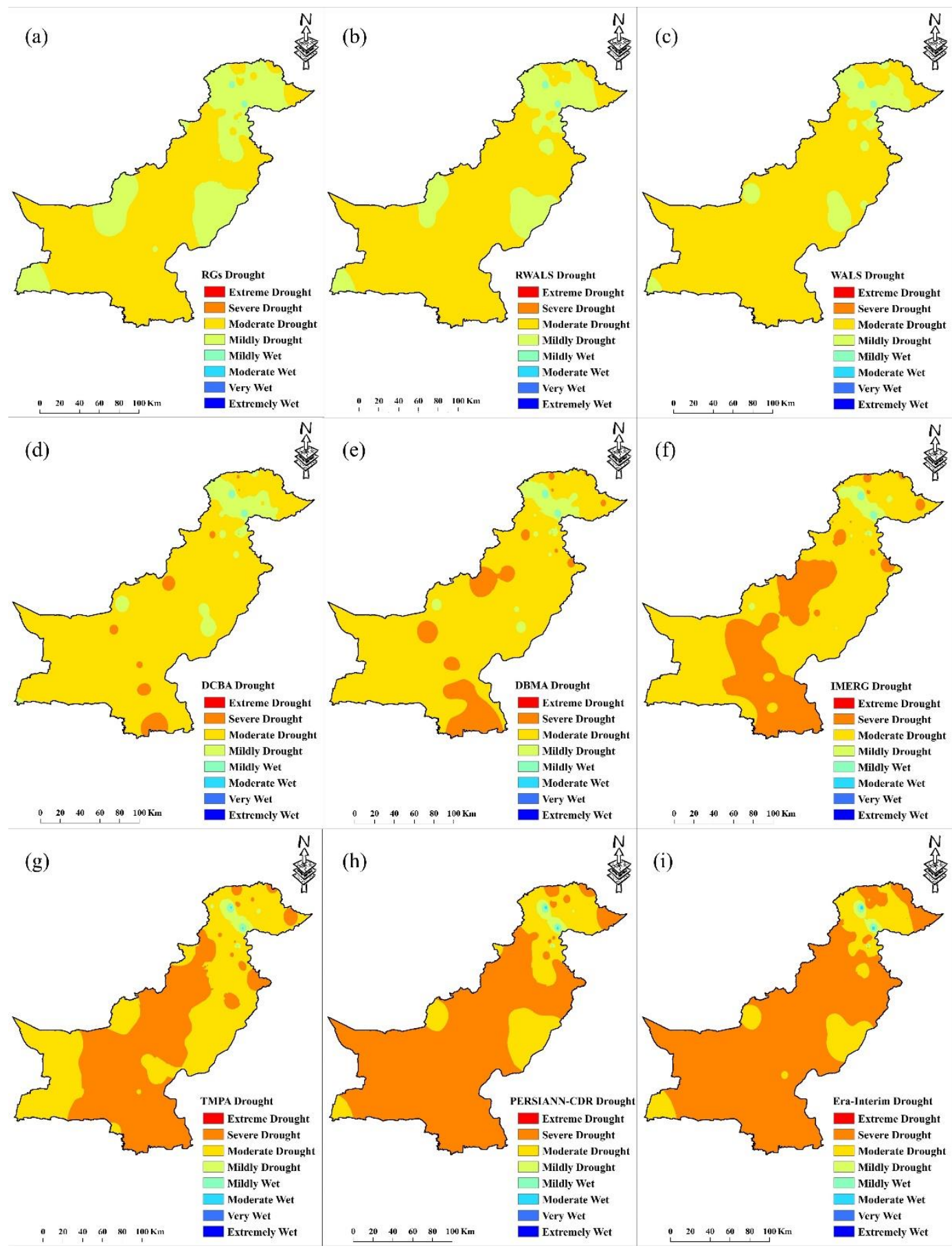

Figure 4. Spatial distribution drought (SPI-3) across Pakistan during winter season in the representative drought year (2008), (a) RGs, (b) RWALS-MSPD, (c) WALS-MSPD, (d) DCBA-MSPD, (e) DBMA-MSPD, (f) IMERG, (g) TMPA, (h) PERSIANNCDR, and (i) ERA-Interim.

The regional-scale assessment shows that the glacial region has mild drought conditions, with few exceptions showing moderate drought. The regional average SPI-3 values for RGs, RWALS, WALS, DCBA, DBMA, IMERG, TMPA, PERSIANN-CDR, and ERAInterim across the glacial region are $-0.34,-0.41,-0.50,-0.58,-0.66,-0.74,-0.81,-0.90$, and -0.95 , respectively. The severity of drought is relatively high in the humid region as 
compared with the glacial region. The maximum and minimum RG-based SPI-3 drought values of the humid region are -0.87 and -0.26 . The average regional SPI-3 values are $-0.78,-0.89,-0.98,-1.10,-1.22,-1.34,-1.46,-1.61$, and -1.76 for WALS, DCBA, DBMA, IMERG, TMPA, PERSIANN-CDR, and ERA-Interim, respectively.

The arid region is characterized by mild to moderate drought conditions. The maximum and minimum SPI-3 values for RGs in arid region are -1.39 and -0.63 at A-RG10 and A-RG12, respectively. The average regional SPI-3 values for WALS, DCBA, DBMA, IMERG, TMPA, PERSIANN-CDR, and ERA-Interim are $-0.87,-0.98,-1.11,-1.20,-1.31,-1.42$, $-1.48,-1.62$, and -1.76 , respectively. The hyper-arid region has an almost monotonic RG-based distribution of drought with maximum and minimum SPI-3 values of -0.86 and -0.50 at HA-RG3 and HA-RG24, respectively. The regional average SPI-3 values for WALS, DCBA, DBMA, IMERG, TMPA, PERSIANN-CDR, and ERA-Interim are -0.87 , $-0.99,-1.10,-1.19,-1.30,-1.44,-1.55,-1.64$, and -1.76 , respectively.

Figure 5 shows the spatial distribution of SPI- 3 based drought severity during the premonsoon season across different climate regions of Pakistan. Overall, Figure 5a (drought estimates from RGs) shows mild drought conditions in Pakistan with an average SPI-3 value of -0.59 , which is increasing from RWALS-MSPD $(-0.72)$ toward the ERA-Interim with a magnitude of -1.27 (moderate drought). MSPDs have outperformed all the individual SPDs where high accuracy has been observed for RWALS, WALS, and DCBA-MSPDs, respectively.

On the regional scale, overall, mildly drought conditions are observed for RGs, all MSPDs, IMERG, and TMPA, while moderate drought for PERSIANN-CDR and ERAInterim. RGs show moderate drought at G-RG18, G-RG6, and G-RG2 with SPI-3 values of $-1.28,-1.16$, and -1.07 , respectively. Contrarily, a moderate wet condition is observed at G-RG4 with an SPI-3 of 1.12, while mild wetness is observed at most of the RGs located at the extreme south of glacial region. RGs, RWALS, WALS, DCBA, and DBMAMSPDs depicted mildly wet conditions across the humid region with SPI-3 values of $0.14,0.21,0.30,0.43$, and 0.58 , respectively. On the other hand, the intensity of wet and drought conditions is increasing in the case of SPDs, i.e., RGs present mildly wet and drought conditions, and MSPDs are depicting moderate wet and drought conditions. The SPI-3 values for IMERG, TMPA, PERSIANN-CDR, and ERA-Interim in the humid region are $0.74,0.91,1.08$, and 1.17 , respectively. The arid region has experienced mildly drought conditions when drought is assessed using RGs and all MSPDs. The average regional SPI-3 values for RGs, RWALS, WALS, DCBA, and DBMA-MSPDs are -0.54 , $-0.71,-0.77,-0.85$, and -0.98 , respectively. However, individual SPDs have depicted moderate drought in the arid region with regional SPI-3 values of $-1.10,-1.18,-1.36$, and -1.44 for IMERG, TMPA, PERSIANN-CDR, and ERA-Interim, respectively. RGs and RWALS- and WALS-MSPDs have very similar and close estimates of drought in hyper-arid region depicting mildly drought with regional SPI-3 values of -0.72 (RGs), -0.83 (RWALSMSPD), and -0.97 (WALS-MSPD). DCBA and DBMA-MSPDs, IMERG, and TMPA SPDs presented moderate drought, while PERSIANN-CDR and ERA-Interim depicted severe drought conditions in the hyper-arid region. The average regional values for DCBA, DBMA, IMERG, TMPA, PERSIANN-CDR, and ERA-Interim are $-1.05,-1.14,-1.29,-1.41,-1.71$, and -1.58 respectively. 

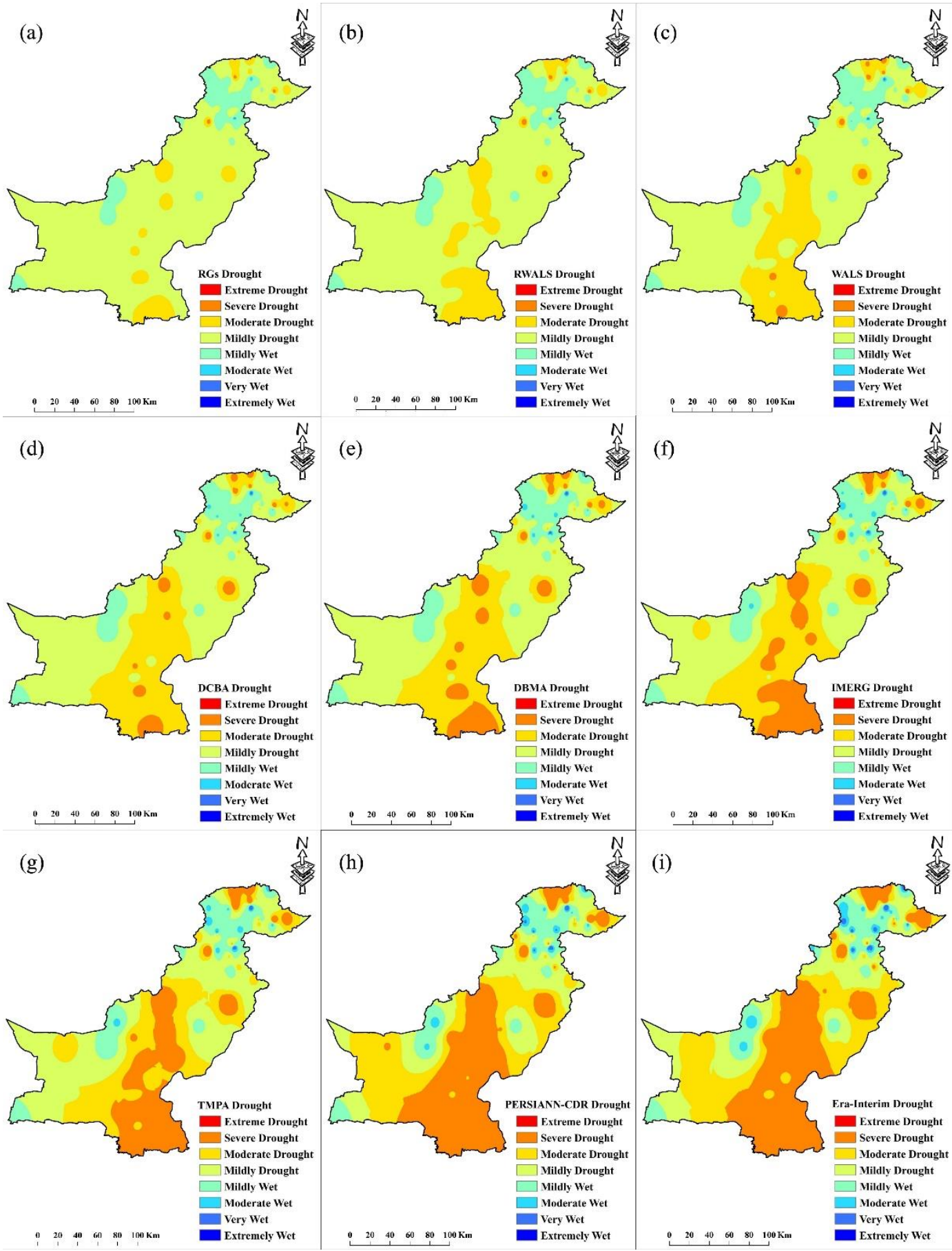

Figure 5. Spatial distribution drought (SPI-3) across Pakistan during pre-monsoon season in the representative drought year (2008), (a) RGs, (b) RWALS-MSPD, (c) WALS-MSPD, (d) DCBA-MSPD, (e) DBMA-MSPD, (f) IMERG, (g) TMPA, (h) PERSIANN-CDR, and (i) ERA-Interim.

The spatial distribution of drought assessed using SPI-3 during the post-monsoon season across Pakistan is shown in Figure 6. Generally, Figure 6 shows the drought in glacial region, relatively mild drought (wetness) in humid region in contrast to mild to moderate drought in arid and hyper-arid regions. RGs, MSPDs, and SPDs (except PERSIANN-CDR and ERA-Interim) demonstrated mild drought, while PERSIANN-CDR and ERA-Interim depicted moderate drought conditions across all of Pakistan. The average SPI-3 values across Pakistan are $-0.43,-0.51,-0.63,-0.70,-0.82,-0.93,-0.97,-1.10$, and -1.18 , 
respectively, for RGs, RWALS, WALS, DCBA, DBMA, IMERG, TMPA, PERSIANN-CDR, and ERA-Interim.

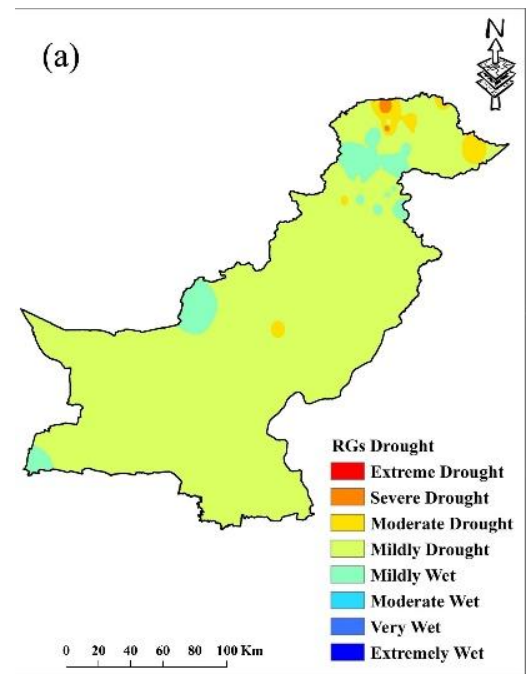

(b)

(d)

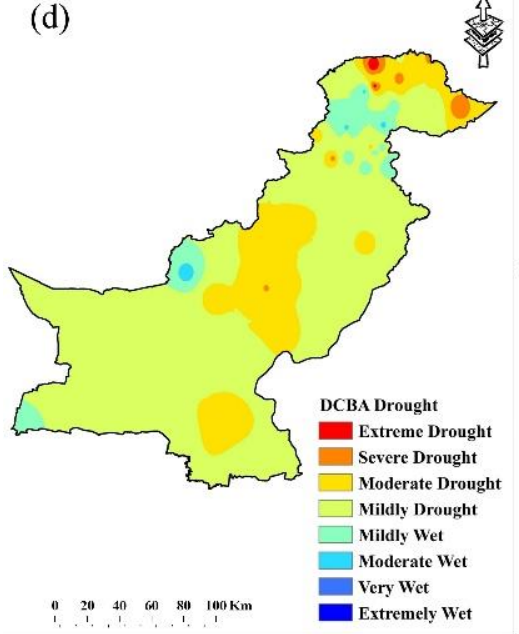

(g)

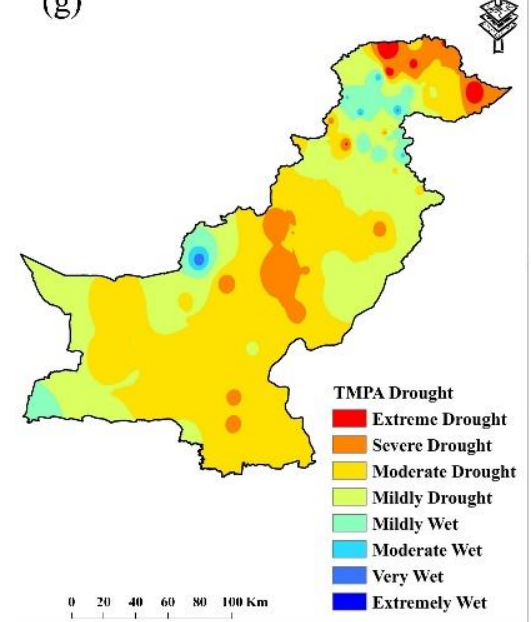

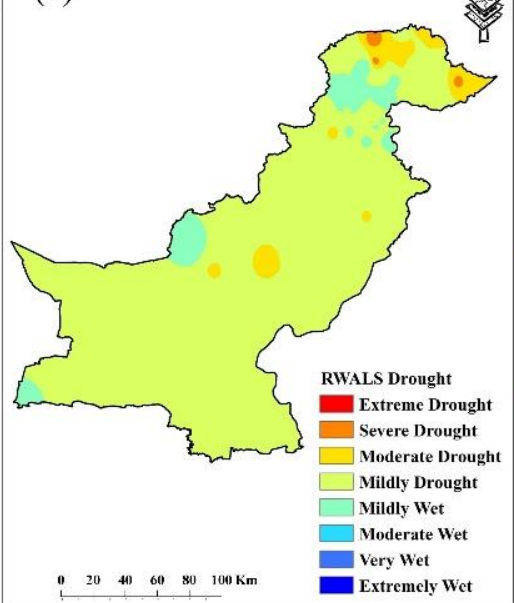

(e)

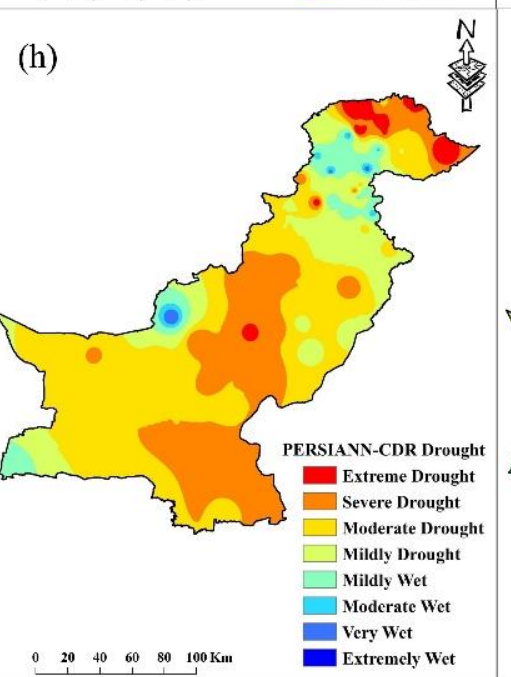

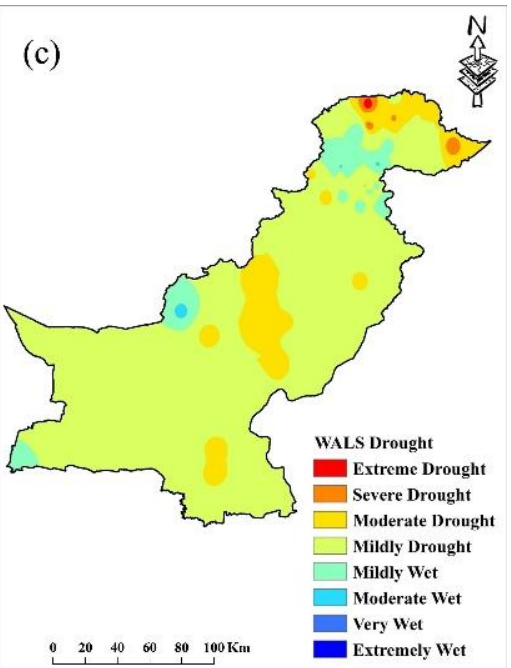
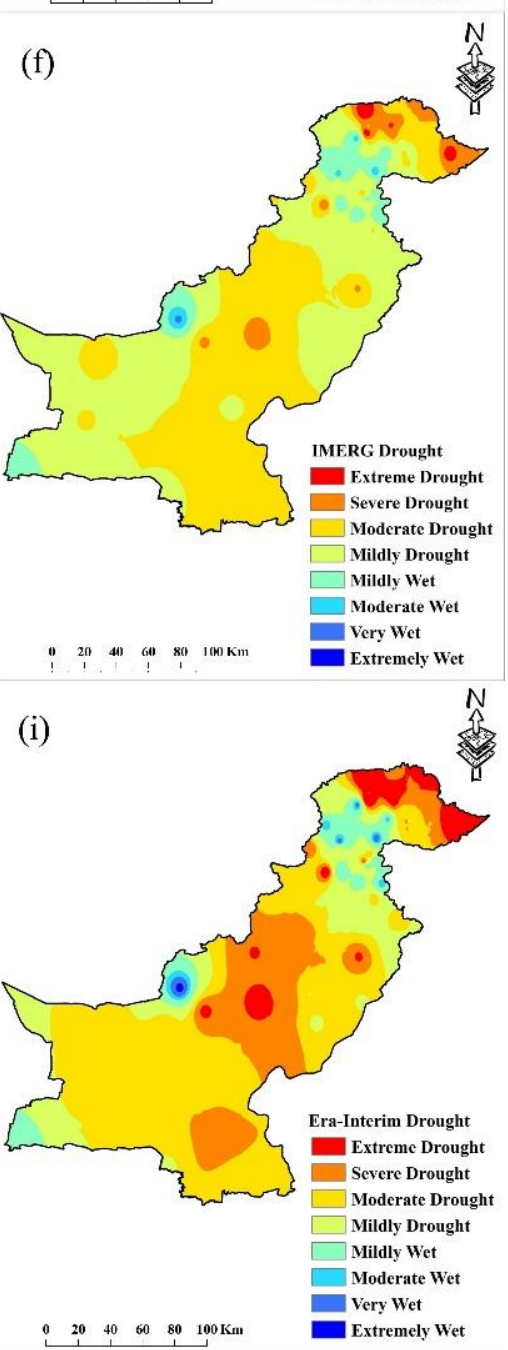

Figure 6. Spatial distribution drought (SPI-3) across Pakistan during post-monsoon season in the representative drought year (2008), (a) RGs, (b) RWALS-MSPD, (c) WALS-MSPD, (d) DCBA-MSPD, (e) DBMA-MSPD, (f) IMERG, (g) TMPA, (h) PERSIANN-CDR, and (i) ERA-Interim. 
The drought severity in glacial region is ranging from mildly drought (RGs, RWALS, and WALS) to severe drought (PERSIANN-CDR and ERA-Interim). Drought in the glacial region is showing a decreasing trend from the extreme north of glacial region toward the extreme south. The regional average SPI-3 values for RGs, RWALS, WALS, DCBA, DBMA, IMERG, TMPA, PERSIANN-CDR, and ERA-Interim are $-0.77,-0.89,-0.98$, $-1.09,-1.22,-1.35,-1.46,-1.64$, and -1.84 , respectively. Mild wet conditions are observed at the extreme north of the humid region, which is gradually changing to mild drought toward the arid region (extreme south of the region). The maximum/minimum RGs-based wet and drought SPI-3 values are $0.46 / 0.22$ and $-1.19 /-0.23$, respectively. The regional average SPI-3 values for RGs, RWALS, WALS, DCBA, DBMA, IMERG, TMPA, PERSIANN-CDR, and ERA-Interim are $-0.14,-0.19,-0.25,-0.30,-0.34,-0.39,-0.42$, -0.53 , and -0.56 , respectively.

Mild to moderate drought conditions are observed for all the input precipitation datasets in the arid region. However, the intensity of drought is increasing from RGs to MSPDs toward the SPDs (Era-Interim). The maximum and minimum RGs-based SPI-3 values in arid regions are -1.09 and -0.14 at A-RG10 and A-RG15, respectively. Moreover, the regional average SPI-3 values are $-0.51,-0.60,-0.67,-0.78,-0.91,-0.99,-1.10$, -1.26, and -1.37 for RGs, RWALS, WALS, DCBA, DBMA, IMERG, TMPA, PERSIANNCDR, and ERA-Interim, respectively. The hyper-arid region mostly presented mild drought (except for a few RGs where moderate drought is observed) conditions for RGs, RWALS, and WALS. However, the intensity of drought is increasing from DCBA and DBMA toward the PERSIANN-CDR. The regional average SPI-3 values for RGs, RWALS, WALS, DCBA, DBMA, IMERG, TMPA, PERSIANN-CDR, and ERA-Interim are $-0.47,-0.58,-0.70,-0.81$, $-0.88,-0.98,-1.06,-1.29$, and -1.15 , respectively.

\subsection{Regional-Scale Assessment of SPDs/MSPDs in Drought Monitoring}

The performance of SPDs/MSPDs on a regional scale is assessed using the precipitation deficit estimated based on monthly aggregates at 1, 3, and 12 months (SPI-1, SPI-3, and SPI-12), which are taken as representatives for short, medium, and long term drought, respectively. The time-series analyses of drought across each climate region are presented for RRGs and RPs. Moreover, the same statistical indices (MAD, RMSE, and MAPD) are used to assess the regional-scale performance of SPDs/MSPDs against the RGs. Since RRGs and RPs represent the nature of a climate region reasonably well, therefore, the potential of SPDs and MSPDs in each climate region against RGs is assessed using the abovementioned statistical indices. Generally, MSPDs have accurately captured the drought intensity/magnitude as well as the distribution pattern (at both spatial and temporal scales) of drought during the study period. However, on the other hand, SPDs performed relatively poorer (worst performance is observed for PERSIANN-CDR and ERA-Interim) to capture the trend and intensity of the drought. The detailed results are discussed below.

\subsubsection{SPI-1}

Figure 7 shows the variations of SPI-1 across different climate regions in comparison with drought estimates from RGs during 2000-2015. The left panel of Figure 7 represents the SPI-1 estimates from RGs and MSPDs, while the right panel shows the comparison of SPDs with RGs. RWALS-MSPD has the missing data 2000-2006 due to the combination of different merging SPDs considered in the development of RWALS-MSPD. The figure shows that MSPDs and SPDs have captured the variation trend of drought/wet conditions across all climate regions fairly well. However, the magnitude of SPI (drought severity) is increasing from RGs to MSPDs and individual SPDs. Overall, the analyses show that years 2000 to 2002 are the major drought years across all climate regions while 2009 to 2011 are the wet years, supporting the findings of Adnan and Ullah (2020). 

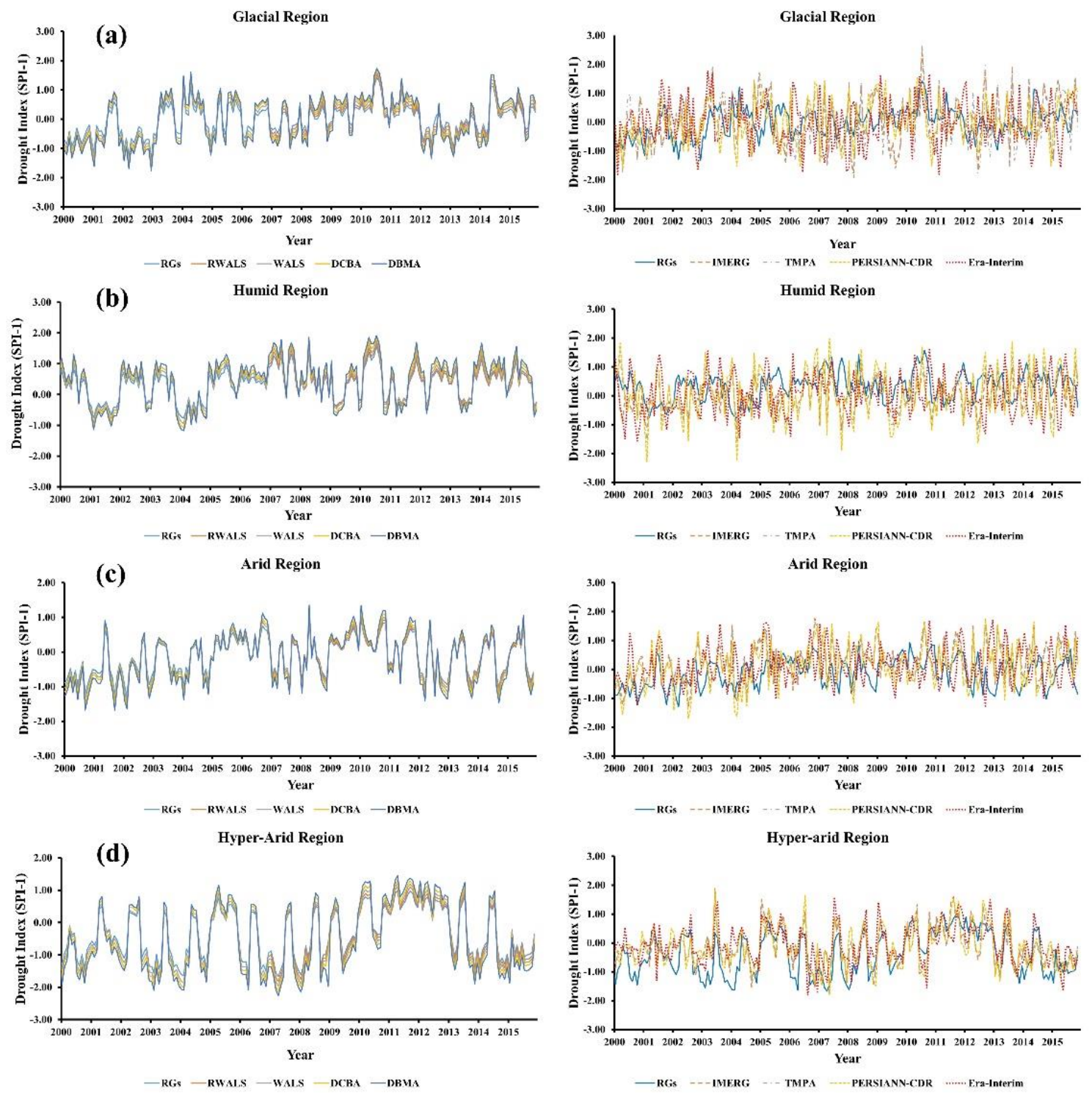

Figure 7. (a-d) SPI-1 drought index estimated using RGs and MSPDs (left panel) and SPDs (right panel) across all four climate regions.

Results show that all precipitation datasets have presented drought and wet conditions with reasonable accuracy in the glacial region (Figure 7 and Table 4). The annual precipitation of the glacial region is ranging from a minimum of around $200 \mathrm{~mm}$ to a maximum of around $400 \mathrm{~mm}$ (estimated from collected data obtained from PMD/WAPDA during 2000-2015). Severe drought is observed in the year 2000 (the minimum/maximum SPI-1 values are ranging from $-0.24 /-1.29$ for RGs to $-1.03 /-2.21$ for ERA-Interim), while 2010 is the wettest across the glacial region (minimum/maximum SPI-1 values are $0.13 / 1.96$ for RGs and 0.53/2.72 ERA-Interim, respectively).

The humid nature of humid region is depicted in Figure $7 \mathrm{~b}$, where maximum years have shown mild to extreme wet conditions. Year 2010 is the wettest year with maximum/minimum SPI-1 values 1.85/0.25 for RGs and 2.75/0.81 for ERA-Interim, respectively. On the other hand, the years 2001 and 2004 are the driest years representing mild drought (RGs and MSPDs) to moderate drought (PERSIANN-CDR and ERA-Interim). 
Table 4. Performance assessment of SPDs/MSPDs on a regional scale using SPI-1 estimated from RGs as a reference.

\begin{tabular}{|c|c|c|c|c|}
\hline Climate Region & SPDs/MSPDs & MAD & RMSD & MAPD \\
\hline \multirow{8}{*}{ Glacial } & RAWALS & 0.683 & 0.972 & 9.311 \\
\hline & WALS & 0.853 & 1.157 & 12.365 \\
\hline & DCBA & 1.059 & 1.268 & 19.532 \\
\hline & DBMA & 1.362 & 1.453 & 27.789 \\
\hline & IMERG & 1.439 & 1.632 & 33.985 \\
\hline & TMPA & 1.748 & 1.722 & 39.108 \\
\hline & $\begin{array}{l}\text { PERSIANN- } \\
\text { CDR }\end{array}$ & 1.951 & 1.738 & 44.761 \\
\hline & Era-Interim & 2.011 & 1.931 & 47.316 \\
\hline \multirow{8}{*}{ Humid } & RAWALS & 1.038 & 1.117 & 8.186 \\
\hline & WALS & 1.158 & 1.258 & 13.586 \\
\hline & DCBA & 1.559 & 1.371 & 21.592 \\
\hline & DBMA & 1.695 & 1.577 & 25.623 \\
\hline & IMERG & 2.018 & 1.675 & 32.771 \\
\hline & TMPA & 2.365 & 1.768 & 37.195 \\
\hline & $\begin{array}{l}\text { PERSIANN- } \\
\text { CDR }\end{array}$ & 2.531 & 1.796 & 43.257 \\
\hline & Era-Interim & 2.644 & 1.956 & 47.974 \\
\hline \multirow{8}{*}{ Arid } & RAWALS & 0.569 & 0.891 & 7.126 \\
\hline & WALS & 0.648 & 0.921 & 10.012 \\
\hline & DCBA & 0.707 & 1.147 & 16.353 \\
\hline & DBMA & 0.873 & 1.246 & 21.797 \\
\hline & IMERG & 0.985 & 1.344 & 27.829 \\
\hline & TMPA & 1.361 & 1.497 & 32.179 \\
\hline & $\begin{array}{l}\text { PERSIANN- } \\
\text { CDR }\end{array}$ & 1.733 & 1.558 & 40.944 \\
\hline & Era-Interim & 1.887 & 1.672 & 42.687 \\
\hline \multirow{8}{*}{ Hyper-arid } & RAWALS & 0.238 & 0.816 & 5.131 \\
\hline & WALS & 0.583 & 0.895 & 8.680 \\
\hline & DCBA & 0.730 & 0.985 & 12.004 \\
\hline & DBMA & 0.832 & 1.048 & 17.561 \\
\hline & IMERG & 0.879 & 1.218 & 21.013 \\
\hline & TMPA & 1.135 & 1.332 & 24.392 \\
\hline & $\begin{array}{c}\text { PERSIANN- } \\
\text { CDR }\end{array}$ & 1.495 & 1.478 & 32.504 \\
\hline & Era-Interim & 1.363 & 1.652 & 29.853 \\
\hline
\end{tabular}

The climate conditions in the arid region vary from mild wet (in the west) to severe drought (east) of the arid region, which reflect the nature of the region. SPI-1 represents that most of the years are drought years except for 2005, 2006, 2009, 2010, and 2011 (Figure 7c). Severe drought in the region is experienced during 2000 (2002) with maximum/minimum SPI-1 values of $-1.24 /-0.48(-1.30 /-0.26)$ for RGs to $-2.20 /-1.05(-2.21 /-0.48)$ for ERA-Interim.

The hyper-arid region is characterized by minimal precipitation, extremely high temperature, and mostly by barren land and deserts; therefore, most of the years in the region represent drought except 2005, 2010, 2011, and 2012. The distribution trend of the drought index across the hyper-arid region supports the findings of Jamro et al. (2019). Extreme drought conditions are observed in most of the years, especially in the year 2000. The SPI- 1 index ranges from a minimum of -0.12 for RGs and -0.55 for ERA-Interim to a maximum of -1.45 for RGs and -2.47 for PERSIANN-CDR. Interestingly, ERA-Interim showed relatively better performance in the hyper-arid region, dominating the PERSIANN-CDR.

The Taylor diagram is used to represent the spatial variability (using standard deviation and correlation between SPDs/MSPDs and RGs) of SPI time-series across each climate region. Figure 8 shows the spatial variability of the SPI- 1 time-series of RWALS-MPSD 
against every RG in each climate region. The results depict a relatively high magnitude of standard deviation (STD) and low correlation $(R)$ in the humid region with average values of 0.50 and 0.65 , respectively. The STD/ $R$ for RWALS-MSPD in the glacial and arid regions are $0.65 / 0.74$ and $0.56 / 0.80$, respectively. Comparatively, lower deviation and the highest correlation between RWALS-MSPD and RGs are observed in the hyper-arid region with average values of 0.49 and 0.82 , respectively. It should be noted that no significant spatial variability has been observed within the RGs/pixels in each climate region.
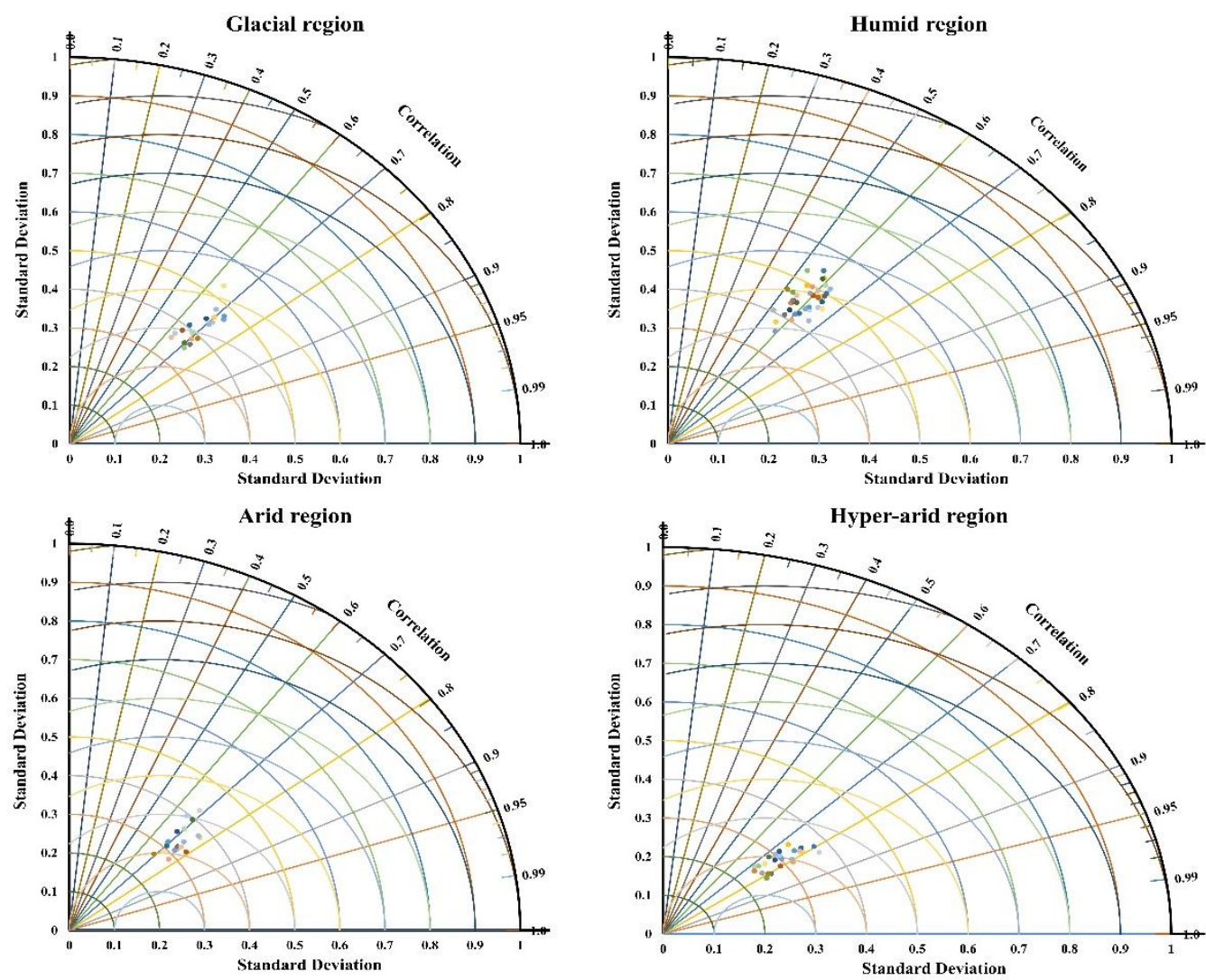

Figure 8. Taylor diagram shows the spatial variability of SPI-1 time-series of RWALS-MPSD against every RG in each climate region.

The variability is also calculated for remaining MSPDs and SPDs, and the results demonstrated no significant spatial variation in the drought estimates across each climate region. The mean STD $/ R$ values for WALS-MSPD in the glacial, humid, arid, and hyper-arid regions are $0.81 / 0.69,0.92 / 0.59,0.63 / 0.74$, and $0.53 / 0.79$, respectively. Similarly, STD/ $R$ for DCBA-MSPD (DBMA-MSPD) are 0.89/0.69 (0.98/0.64), 0.99/0.53 (1.07/0.50), 0.71/0.68 (0.79/0.64), and 0.60/0.75 (0.68/0.71), respectively, across the glacial, humid, arid, and hyper-arid regions. IMERG is the best performing member among the set of SPDs, while ERA-Interim has the worst performance. The STD/R for IMERG (EraInterim) across the glacial, humid, arid, and hyper-arid regions are 1.15/0.54 (1.38/0.42), $1.21 / 0.44(1.50 / 0.32), 0.92 / 0.59(1.22 / 0.46)$, and $0.78 / 0.66(1.06 / 0.53)$, respectively.

Table 4 represents the magnitude of statistical indices of SPDs/MSPDs-based SPI-1 considering RGs as a reference. Table 4 shows the maximum error in the humid region followed by the glacial region, which is decreasing toward the hyper-arid region. Statistical indices confirm the high performance of RWALS-MSPD, depicting high accurate drought estimation with MAPD values less than 10\%. Moreover, WALS- and DCBA-MSPDs depicted good performance in glacial, humid, and arid regions $(20 \%<\mathrm{MAPD}<10 \%)$. The results show that high (WALS-MSPD) and good (DCBA-MSPD) performances are observed across 
the hyper-arid region. As compared with MSPDs, SPDs have significantly low accuracies estimated using MAD, RMSD, and MAPD.

\subsubsection{SPI-3}

SPI-3 has an almost close estimate of SPI values and statistical indices values compared with SPI-1 (Figure 9 and Table 5). Figure 9 represents the SPI-3 estimates of SPDs (right panel)/MSPDs (left panel) compared to SPI-3 estimates from RGs across all climate regions during 2000-2015. Severe to extreme drought conditions are observed in the year 2000 (high drought magnitude with maximum/minimum SPI-3 values of $-1.76 /-0.41$ for RGs and $-2.68 /-1.17$ for ERA-Interim), while mild to very wet conditions are depicted in the year 2010 (minimum/maximum SPI-3 values of $0.05 / 1.30$ for RGs and 0.10/2.21 for ERA-Interim). The humid region receives maximum precipitation across all climate regions of Pakistan, and thus, it is depicted in Figure 9b, where most of the years are wet, ranging from mild to very wet conditions. SPI-3 estimates from all the precipitation sources represent mildly wet to extremely wet conditions with the exceptions in the years 2001 and 2004 (drought years). The maximum/minimum SPI-3 values for humid region are $-0.90 /-0.25$ for RGs and $-1.96 /-0.79$ for ERA-Interim. On the other hand, 2010 (2015) are the wet years across the humid region with maximum/minimum values of $1.85 / 0.26$ $(1.26 / 0.19)$ for RGs and 2.75/0.81 (2.73/0.64) for ERA-Interim.
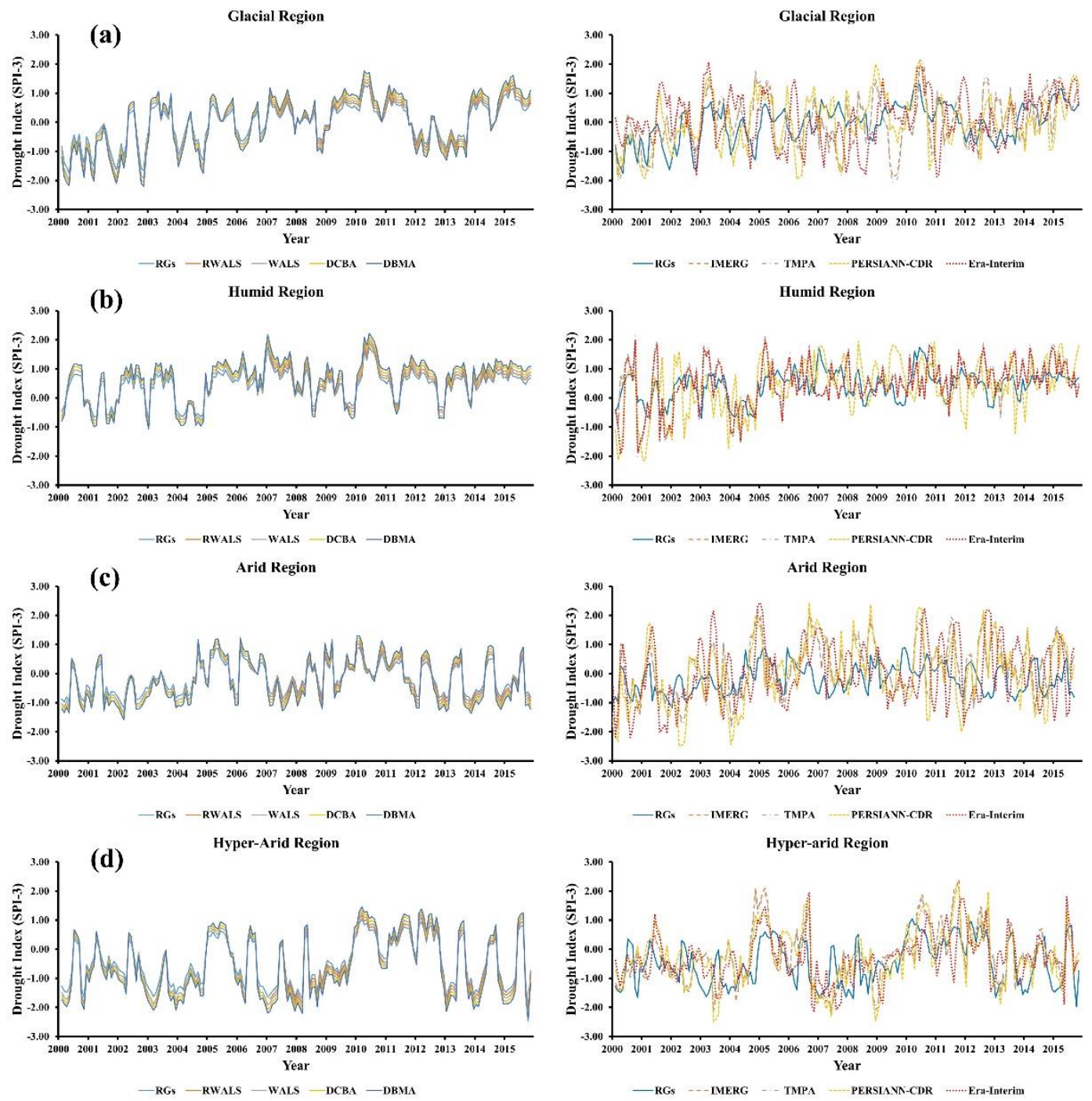

Figure 9. (a-d) SPI-3 drought index estimated using RGs and MSPDs (left panel) and SPDs (right panel) across all four climate regions. 
Table 5. Performance assessment of SPDs/MSPDs on a regional scale using SPI-3 estimated from RGs as a reference.

\begin{tabular}{|c|c|c|c|c|}
\hline Climate Region & SPDs/MSPDs & MAD & RMSD & MAPD \\
\hline \multirow{8}{*}{ Glacial } & RAWALS & 0.592 & 0.897 & 9.205 \\
\hline & WALS & 0.794 & 1.022 & 13.718 \\
\hline & DCBA & 0.966 & 1.193 & 19.887 \\
\hline & DBMA & 1.241 & 1.318 & 25.043 \\
\hline & IMERG & 1.388 & 1.446 & 31.191 \\
\hline & TMPA & 1.623 & 1.566 & 37.411 \\
\hline & PERSIANN-CDR & 1.875 & 1.656 & 43.526 \\
\hline & Era-Interim & 1.976 & 1.746 & 48.667 \\
\hline \multirow{8}{*}{ Humid } & RAWALS & 0.942 & 1.102 & 9.066 \\
\hline & WALS & 1.074 & 1.181 & 12.988 \\
\hline & DCBA & 1.410 & 1.272 & 19.700 \\
\hline & DBMA & 1.640 & 1.468 & 24.352 \\
\hline & IMERG & 1.924 & 1.520 & 31.019 \\
\hline & TMPA & 2.229 & 1.622 & 35.793 \\
\hline & PERSIANN-CDR & 2.439 & 1.705 & 41.383 \\
\hline & Era-Interim & 2.561 & 1.799 & 44.287 \\
\hline \multirow{8}{*}{ Arid } & RAWALS & 0.485 & 0.873 & 8.107 \\
\hline & WALS & 0.554 & 0.903 & 9.585 \\
\hline & DCBA & 0.671 & 1.034 & 15.824 \\
\hline & DBMA & 0.844 & 1.142 & 20.171 \\
\hline & IMERG & 1.148 & 1.237 & 25.908 \\
\hline & TMPA & 1.280 & 1.384 & 31.483 \\
\hline & PERSIANN-CDR & 1.639 & 1.454 & 39.172 \\
\hline & Era-Interim & 1.705 & 1.597 & 43.187 \\
\hline \multirow{8}{*}{ Hyper-arid } & RAWALS & 0.209 & 0.761 & 6.394 \\
\hline & WALS & 0.484 & 0.790 & 9.569 \\
\hline & DCBA & 0.602 & 0.859 & 11.861 \\
\hline & DBMA & 0.813 & 0.990 & 16.503 \\
\hline & IMERG & 0.837 & 1.125 & 19.897 \\
\hline & TMPA & 1.063 & 1.219 & 22.962 \\
\hline & PERSIANN-CDR & 1.386 & 1.400 & 29.878 \\
\hline & Era-Interim & 1.296 & 1.322 & 28.974 \\
\hline
\end{tabular}

The conditions across the arid region are varying from wet (western areas) to drought (eastern plain areas). However, the SPI-3 index presents mostly drought across the region except for in 2005, 2006, 2009, 2010, and 2011 (Figure 9c). Severe drought is depicted in the years 2000 and 2002. The maximum/minimum drought values in the year 2000 are $-1.23 /-0.28$ for RGs and -2.20 / -0.61 for ERA-Interim. All the precipitation datasets show drought conditions in the hyper-arid region (except for the years 2005, 2010, 2011, and 2012), with severity ranging from extremely drought to mildly drought (Figure 9d). The SPI-3 drought values for the year 2000 in the hyper-arid region are ranging from -0.33 to -1.45 for RGs and -0.79 to -2.31 for PERSIANN-CDR. Overall, the results show that MSPDs have accurately followed the SPI-3 time-series with relatively closer estimates than RGs. SPDs followed the SPI-3 pattern but failed to accurately represent the drought magnitude and intensity in all the climate regions, especially ERA-Interim and PERSIANN-CDR.

A Taylor diagram for the RWALS-MSPD time-series of SPI-3 across each climate region is shown in Figure 10. SPI-3 also did not show any spatial variability among the stations (RPs) across each climate region. However, the accuracy increases significantly (minimum STD and maximum $R$ ) as compared with SPI-1. The STD/ $R$ values for RWALS (WALS) across glacial, humid, arid, and hyper-arid regions are 0.61/0.78 (0.75/0.73), 0.68/0.70 (0.78/0.64), 0.53/0.84 $(0.62 / 0.77)$, and $0.40 / 0.87(0.46 / 0.83)$. Similarly, the STD/ $R$ for DCBA (DBMA) MSPDs are $0.81 / 0.69(0.89 / 0.64), 0.89 / 0.59(0.96 / 0.54), 0.70 / 0.73(0.75 / 0.69)$, and $0.53 / 0.79(0.60 / 0.75)$, 
respectively, across glacial, humid, arid, and hyper-arid regions. The individual SPDs show relatively higher deviation and low correlation as compared with RGs. The STD/ $R$ values for IMERG (Era-Interim) across glacial, humid, arid, and hyper-arid regions are 1.02/0.59 $(1.25 / 0.48), 1.11 / 0.47(1.34 / 0.36), 0.87 / 0.62(1.15 / 0.51)$, and $0.68 / 0.69(0.94 / 0.59)$, respectively.
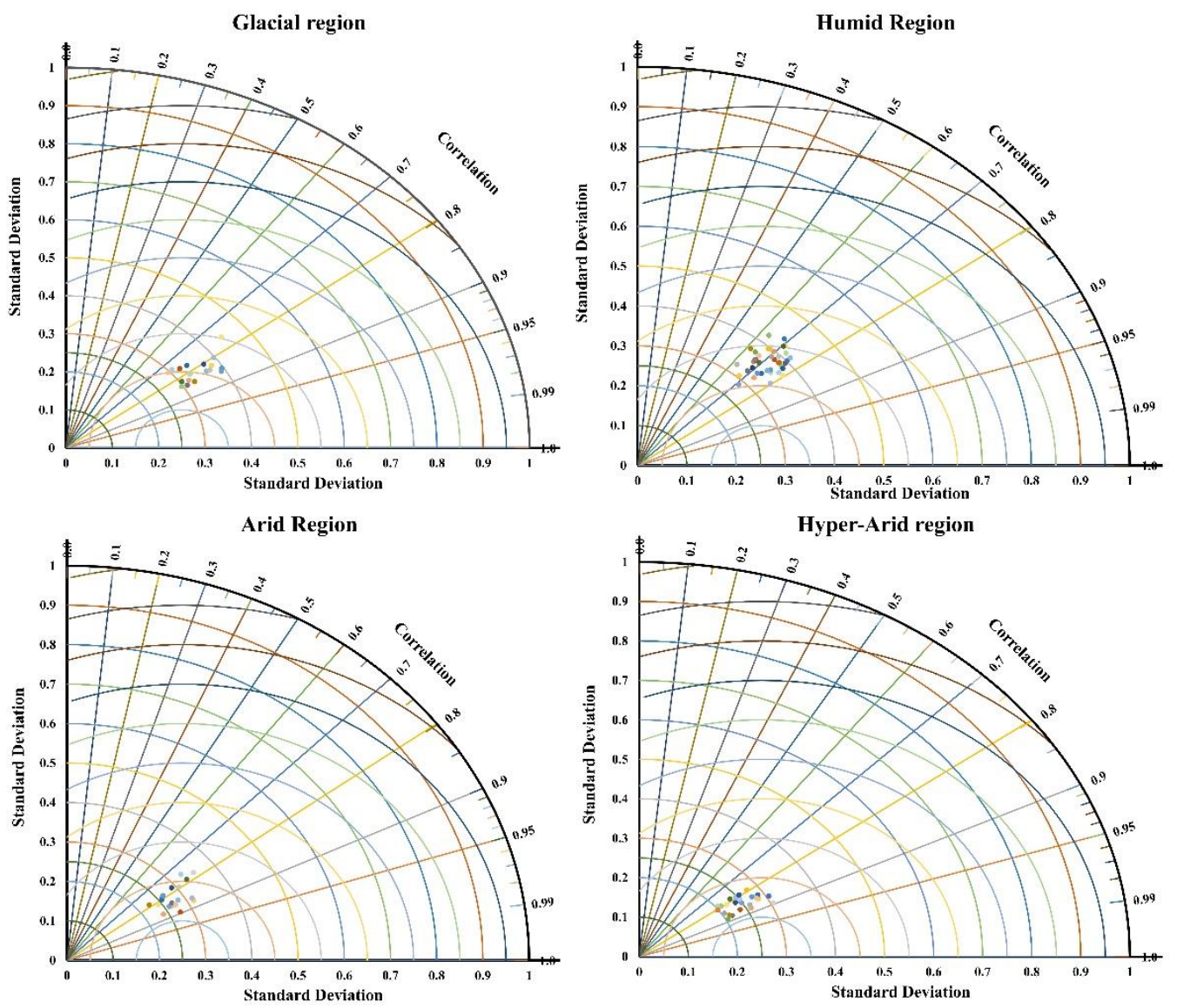

Figure 10. Taylor diagram shows the spatial variability of SPI-3 time-series of RWALS-MPSD against every RG in each climate region.

The magnitude of statistical indices of SPDs/MSPDs (deviation from RGs-based estimated SPI-3) is presented in Table 5. The maximum magnitude of errors is observed in the humid region followed by the glacial region. The magnitude of indices reduced significantly toward the hyper-arid region. RWALS-MSPD showed significantly improved performance across all the climate regions with MAPD values lower than $10 \%$. WALS- and DCBA-MSPDs depicted good performance across glacial and humid regions and high accurate drought estimates across arid and hyper-arid regions. Individual SPDs have lower accuracy as compared with MSPDs. Moreover, ERA-Interim outperformed the PERSIANN-CDR across hyper-arid region.

\subsubsection{SPI-12}

Figure 11 represents the variations of SPI-12 across all climate regions during 2000-2015. The glacial region (Figure 11a) depicts severe/moderate drought in the years 2000, 2001, 2006, 2008, 2012, and 2013. Higher drought severity is observed in the year 2001 with maximum/minimum SPI-12 values of $-0.99 /-0.24$ for RGs and $-2.02 /-0.88$ for ERAInterim, respectively. On the other hand, the years 2003, 2005, 2007, 2009, 2010, 2011, 2014, and 2015 are the wet years. SPI-12 in the year 2010 is ranging from 0.40 to 0.92 for RGs and from 1.25 to 1.97 for ERA-Interim. Years 2001, 2004, and 2009 are the drought years in the humid region with severity from mild to moderate drought (based on RGs observations). High drought is observed in the year 2001, with SPI-12 ranging from -0.17 to -0.67 for 
RGs and from -0.63 to -1.50 for ERA-Interim (Figure 11b). On the other hand, 2010 is the wettest year with SPI-12 values in the range of 0.26-0.94 for RGs and 1.08-2.02 for ERA-Interim.
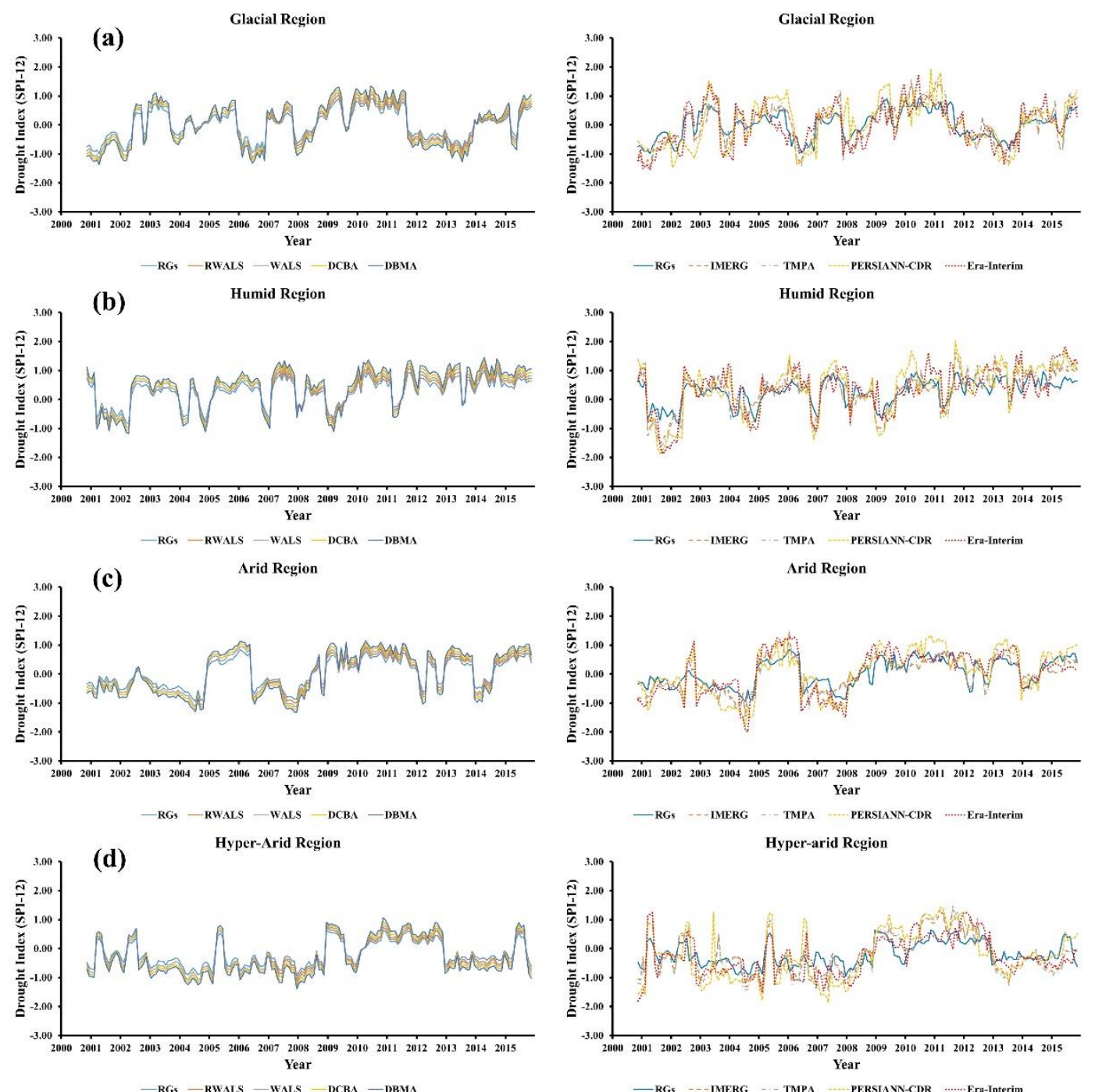

Figure 11. (a-d) SPI-12 drought index estimated using RGs and MSPDs (left panel) and SPDs (right panel) across all four climate regions.

The arid region (Figure 11c) has experienced drought in most of the years except for 2005, 2009, 2010, 2011, and 2015. The year 2004 has the highest drought severity with maximum/minimum SPI-12 values of $-0.95 /-0.23$ for RGs and $-1.95 /-0.93$ for ERAInterim, respectively. Moreover, the hyper-arid region has experienced drought in all years except for 2010-2012 (Figure 11d), where 2010 is the wet year with SPI-12 ranging from -0.09 to 0.64 for RGs and from -0.23 to 1.57 for PERSIANN-CDR. Year 2004 is the driest year for the hyper-arid region with maximum/minimum regional SPI-12 values of $-0.91 /-0.36$ for RGs and $-1.85 /-1.14$ for PERSIANN-CDR.

Figure 12 is the Taylor diagram showing the spatial variability in SPI-12 for RWALSMSPD across all climate regions of Pakistan. The Taylor diagram shows that RRGs (RPs) have approximately similar drought estimates across each climate region and have no significant spatial variability. The mean regional STD/R for RWALS (WALS) MSPDs across glacial, humid, arid, and hyper-arid regions are $0.55 / 0.86(0.66 / 0.82), 0.50 / 0.78(0.61 / 0.74)$, $0.45 / 0.88(0.51 / 0.83)$, and $0.38 / 0.90(0.42 / 0.86)$, respectively. Furthermore, the STD $/ R$ for DCBA (DBMA) are 0.74/0.77 (0.83/0.73), 0.69/0.70 (0.77/0.63), 0.60/0.80 (0.68/0.74), 
and 0.48/0.84 (0.57/0.79), respectively, across glacial, humid, arid, and hyper-arid regions. Finally, IMERG (Era-Interim) has the average STD/R values of $0.85 / 0.64(1.08 / 0.52)$, $0.94 / 0.56$ (1.14/0.45), 0.75/0.70 (1.02/0.57), and 0.65/0.72 (0.88/0.61) across glacial, humid, arid, and hyper-arid regions, respectively. Overall, the results show improvements from SPI-1 to SPI-12 and no significant spatial variability in climate regions. In other words, the RRGs and RPs in every climate region have the potential to represent the temporal distribution of drought.
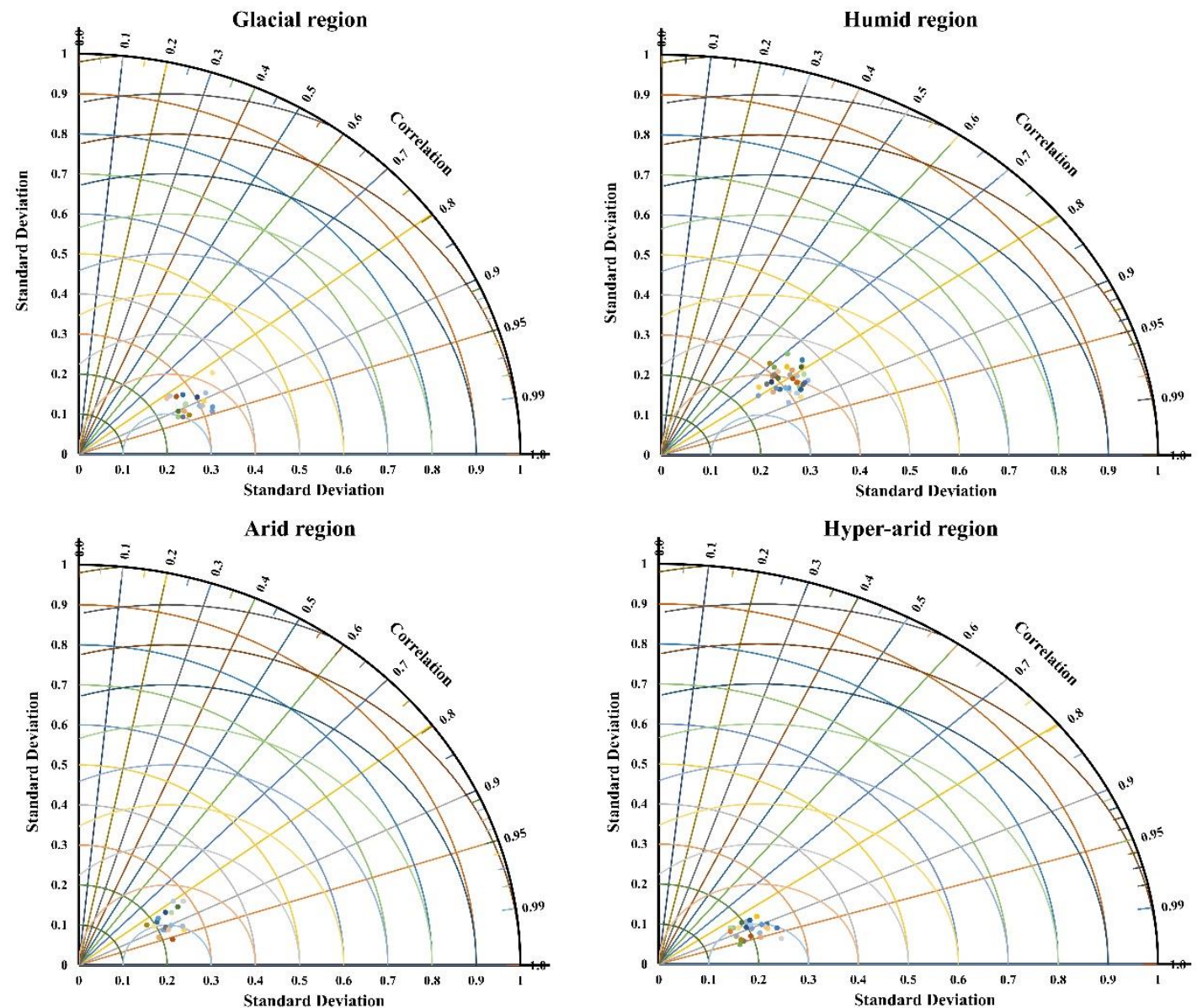

Figure 12. The Taylor diagramshows the spatial variability of SPI-12 time-series of RWALS-MPSD against every RG in each climate region.

The performance of MSPDs and SPDs are significantly improved for SPI-12 as compared with SPI-1 and SPI-3 (shown in Table 6). This is due to the fact that the SPI-12, which is a 12-month moving average of precipitation aggregate, stabilizes the peak of drought and wet months and results in almost stable performance. The performance evaluation of MSPDs and SPDs with respect to RGs (considered as a reference) confirms the superiority of MSPDs over SPDs in all climate regions (Table 6). The poor performance of SPDs is observed in glacial and humid regions, which is improving toward the hyper-arid region. Among the MSPDs, RWALS and WALS have dominated the DCBA and DBMA, while IMERG and TMPA dominated other SPDs in all climate regions. The MAPD for RWALS and WALS showing high accuracy (MAPD <10\%), while DCBA and DBMA presented good accuracy $(10 \%<$ MAPD $<20 \%)$ across all the climate regions (Table 6$)$. Among the SPDs, IMERG and TMPA continued their supremacy over PERSIANN-CDR and ERA-Interim with MAPD ranging from 20 to $30 \%$ in glacial, humid, and arid regions, whereas it was $10 \%$ to $20 \%$ in hyper-arid regions. 
Table 6. Performance assessment of SPDs/MSPDs on a regional scale using SPI-12 estimated from RGs as a reference.

\begin{tabular}{|c|c|c|c|c|}
\hline Climate Region & SPDs/MSPDs & MAD & RMSD & MAPD \\
\hline \multirow{8}{*}{ Glacial } & RAWALS & 0.378 & 0.680 & 6.713 \\
\hline & WALS & 0.467 & 0.851 & 9.479 \\
\hline & DCBA & 0.670 & 0.942 & 13.496 \\
\hline & DBMA & 0.859 & 1.132 & 18.786 \\
\hline & IMERG & 0.977 & 1.244 & 23.448 \\
\hline & TMPA & 1.206 & 1.353 & 29.732 \\
\hline & PERSIANN-CDR & 1.399 & 1.452 & 34.562 \\
\hline & Era-Interim & 1.698 & 1.579 & 38.882 \\
\hline \multirow{8}{*}{ Humid } & RAWALS & 0.607 & 0.892 & 5.309 \\
\hline & WALS & 0.815 & 0.916 & 8.085 \\
\hline & DCBA & 0.942 & 1.152 & 13.096 \\
\hline & DBMA & 1.253 & 1.304 & 17.506 \\
\hline & IMERG & 1.574 & 1.406 & 23.814 \\
\hline & TMPA & 1.803 & 1.455 & 28.744 \\
\hline & PERSIANN-CDR & 1.866 & 1.579 & 34.592 \\
\hline & Era-Interim & 2.179 & 1.628 & 38.935 \\
\hline \multirow{8}{*}{ Arid } & RAWALS & 0.275 & 0.736 & 5.143 \\
\hline & WALS & 0.194 & 0.786 & 7.851 \\
\hline & DCBA & 0.524 & 0.896 & 11.395 \\
\hline & DBMA & 0.678 & 0.987 & 16.356 \\
\hline & IMERG & 0.915 & 1.085 & 21.689 \\
\hline & TMPA & 1.096 & 1.274 & 27.216 \\
\hline & PERSIANN-CDR & 1.486 & 1.386 & 32.057 \\
\hline & Era-Interim & 1.532 & 1.487 & 38.975 \\
\hline \multirow{8}{*}{ Hyper-arid } & RAWALS & 0.145 & 0.624 & 3.921 \\
\hline & WALS & 0.312 & 0.638 & 6.897 \\
\hline & DCBA & 0.403 & 0.746 & 9.882 \\
\hline & DBMA & 0.607 & 0.887 & 12.547 \\
\hline & IMERG & 0.719 & 0.995 & 16.355 \\
\hline & TMPA & 0.885 & 1.105 & 19.615 \\
\hline & PERSIANN-CDR & 1.196 & 1.291 & 28.198 \\
\hline & Era-Interim & 1.120 & 1.214 & 23.478 \\
\hline
\end{tabular}

\subsection{Trend Analyses of Drought Across Climate Regions of Pakistan}

Trends in drought indices (SPI-1, 3, and 12) across all the four climate regions are determined using the MK test with a significance level of 5\% from 2000 to 2015. The analyses of MK test (for SPI-1), including average Kendal's tau values, average Sen's slope, and $p$-values are presented in Table 7. The sign of Sen's slope depicts positive (increasing) or negative (decreasing) trends. Table 7 shows that all the SPDs and MSPDs are depicting an increasing (positive) trend over glacial, humid, and arid regions and a decreasing (negative) trend across the hyper-arid region. The analyses by RGs and MSPDs are statistically significant at $1 \%, 5 \%$, and $10 \%$ significance levels. SPI- 1 shows a relatively low significance level (somewhat closer to SPI-3), which can be observed from Kendal's $\tau$ and Sen's Slope values, as compared with SPI-12. The level of significance is decreasing from RGs to RWALS, WALS, DCBA, and DBMA-MSPDs to SPDs. Tables 8 and 9 represent the MK analyses for SPI-3 and SPI-12, respectively. 
Table 7. MK trend and level of significance for SPI-1 estimated for RGs, SPDs, and MSPDs across all climate regions. The $p$-values less than $0.01,0.05$, and 0.10 show that the trend is significant at the significance level of $1 \%, 5 \%$, and $10 \%$ and marked with $* * * * *$, and $*$, respectively.

\begin{tabular}{|c|c|c|c|c|c|}
\hline SPDs/MSPDs & Parameters & Glacial & Humid & Arid & Hyper-Arid \\
\hline \multirow{3}{*}{ RGs } & Kendal $\tau$ & 0.307 & 0.254 & 0.352 & -0.346 \\
\hline & Sen's Slope & 3.664 & 4.127 & 3.852 & -4.556 \\
\hline & $p$-value & $0.007^{* * *}$ & $0.010^{* * *}$ & 0.024 ** & $0.009^{* * *}$ \\
\hline \multirow{3}{*}{ RWALS } & Kendal & 0.296 & 0.365 & 0.363 & -0.317 \\
\hline & Sen's Slope & 2.333 & 3.883 & 3.789 & -4.256 \\
\hline & $p$-value & $0.007^{* * *}$ & $0.010^{* * *}$ & $0.024^{* *}$ & $0.010^{* * *}$ \\
\hline \multirow{3}{*}{ WALS } & Kendal $\tau$ & 0.199 & 0.317 & 0.358 & -0.283 \\
\hline & Sen's Slope & 2.917 & 3.813 & 3.913 & -4.059 \\
\hline & $p$-value & $0.010^{* * *}$ & $0.024^{* *}$ & $0.028^{* *}$ & $0.010^{* * *}$ \\
\hline \multirow{3}{*}{ DCBA } & Kendal $\tau$ & 0.193 & 0.359 & 0.217 & -0.238 \\
\hline & Sen's Slope & 2.214 & 3.717 & 3.597 & -3.807 \\
\hline & $p$-value & $0.010^{* * *}$ & $0.050 * *$ & 0.042 ** & $0.010^{* * *}$ \\
\hline \multirow{3}{*}{ DBMA } & Kendal $\tau$ & 0.191 & 0.257 & 0.2 & -0.238 \\
\hline & Sen's Slope & 2.159 & 3.125 & 3.581 & -3.766 \\
\hline & $p$-value & $0.040^{* *}$ & 0.059 * & $0.042^{* *}$ & $0.010^{* * *}$ \\
\hline \multirow{3}{*}{ IMERG } & Kendal $\tau$ & 0.217 & 0.25 & 0.188 & -0.200 \\
\hline & Sen's Slope & 2.183 & 3.328 & 2.775 & -3.688 \\
\hline & $p$-value & $0.050 * *$ & 0.059 * & $0.059 *$ & $0.024^{* *}$ \\
\hline \multirow{3}{*}{ TMPA } & Kendal & 0.185 & 0.217 & 0.188 & -0.183 \\
\hline & Sen's Slope & 1.801 & 3.175 & 2.832 & -3.634 \\
\hline & $p$-value & $0.050^{* *}$ & 0.059 * & $0.070 *$ & $0.024^{* *}$ \\
\hline \multirow{3}{*}{ PERSIANN-CDR } & Kendal $\tau$ & 0.144 & 0.183 & 0.153 & -0.108 \\
\hline & Sen's Slope & 1.722 & 3.524 & 2.469 & -2.618 \\
\hline & $p$-value & 0.090 * & $0.070 *$ & $0.072 *$ & $0.050 * *$ \\
\hline \multirow{3}{*}{ Era-Interim } & Kendal $\tau$ & 0.153 & 0.183 & 0.167 & -0.150 \\
\hline & Sen's Slope & 1.811 & 2.935 & 2.432 & -2.667 \\
\hline & $p$-value & 0.090 * & 0.090 * & $0.077 *$ & $0.028^{* *}$ \\
\hline
\end{tabular}

Table 8. MK trend and level of significance for SPI-3 estimated for RGs, SPDs, and MSPDs across all climate regions. The $p$-values less than $0.01,0.05$, and 0.10 show that the trend is significant at the significance level of $1 \%, 5 \%$, and $10 \%$ and marked with ${ }^{* * *},{ }^{* *}$, and ${ }^{*}$, respectively.

\begin{tabular}{cccccc}
\hline SPDs/MSPDs & Parameters & Glacial & Humid & Arid & Hyper-Arid \\
\hline \multirow{2}{*}{ RGs } & Kendal $\tau$ & 0.35 & 0.383 & 0.433 & -0.317 \\
& Sen's Slope & 2.101 & 4.267 & 2.916 & -4.709 \\
& $p$-value & $0.005^{* * *}$ & $0.007^{* * *}$ & $0.010^{* * *}$ & $0.005^{* * *}$ \\
\hline \multirow{2}{*}{ RWALS } & Kendal $\tau$ & 0.333 & 0.317 & 0.433 & -0.350 \\
& Sen's Slope & 2.211 & 4.152 & 2.896 & -4.538 \\
& $p$-value & $0.005^{* * *}$ & $0.007^{* * *}$ & $0.010^{* * *}$ & $0.005^{* * *}$ \\
\hline \multirow{2}{*}{ WALS } & Kendal $\tau$ & 0.323 & 0.3 & 0.333 & -0.273 \\
& Sen's Slope & 1.998 & 4.003 & 2.515 & -4.316 \\
& $p$-value & $0.007^{* * *}$ & $0.012^{* * *}$ & $0.024^{* *}$ & $0.005^{* * *}$ \\
\hline \multirow{2}{*}{ DCBA } & Kendal $\tau$ & 0.283 & 0.3 & 0.3 & -0.237 \\
& Sen's Slope & 1.781 & 3.749 & 2.128 & -4.578 \\
& $p$-value & $0.009^{* * *}$ & $0.024^{* *}$ & $0.028^{* *}$ & $0.007^{* * *}$ \\
\hline \multirow{2}{*}{ DBMA } & Kendal $\tau$ & 0.253 & 0.28 & 0.3 & -0.217 \\
& Sen's Slope & 2.036 & 3.866 & 1.853 & -4.351 \\
& $p$-value & $0.024^{* * *}$ & $0.048^{* *}$ & $0.050^{* *}$ & $0.010^{* * *}$ \\
\hline
\end{tabular}


Table 8. Cont.

\begin{tabular}{cccccc}
\hline SPDs/MSPDs & Parameters & Glacial & Humid & Arid & Hyper-Arid \\
\hline \multirow{2}{*}{ IMERG } & Kendal $\tau$ & 0.232 & 0.253 & 0.255 & -0.183 \\
& Sen's Slope & 1.954 & 3.812 & 1.807 & -3.541 \\
& $p$-value & $0.050^{* * *}$ & $0.059^{* *}$ & $0.077^{* *}$ & $0.024^{* * *}$ \\
\hline \multirow{2}{*}{ TMPA } & Kendal $\tau$ & 0.217 & 0.253 & 0.233 & -0.150 \\
& Sen's Slope & 1.762 & 3.382 & 1.821 & -3.266 \\
& $p$-value & $0.050^{* *}$ & $0.059^{*}$ & $0.077^{*}$ & $0.024^{* *}$ \\
\hline \multirow{3}{*}{ PERSIANN-CDR } & Kendal $\tau$ & 0.207 & 0.223 & 0.217 & -0.117 \\
& Sen's Slope & 1.294 & 3.125 & 1.76 & -3.592 \\
& $p$-value & $0.072^{* *}$ & $0.090^{*}$ & $0.090 *$ & $0.050 *$ \\
\hline \multirow{2}{*}{ Era-Interim } & Kendal $\tau$ & 0.207 & 0.213 & 0.217 & -0.100 \\
& Sen's Slope & 1.208 & 2.807 & 1.531 & -4.465 \\
& $p$-value & $0.072^{*}$ & $0.090^{*}$ & $0.100 *$ & $0.050 * *$ \\
\hline
\end{tabular}

Table 9. MK trend and level of significance for SPI-12 estimated for RGs, SPDs, and MSPDs across all climate regions. The $p$-values less than $0.01,0.05$, and 0.10 show that the trend is significant at the significance level of $1 \%, 5 \%$, and $10 \%$ and marked with ${ }^{* *}, * *$, and $*$, respectively.

\begin{tabular}{|c|c|c|c|c|c|}
\hline SPDs/MSPDs & Parameters & Glacial & Humid & Arid & Hyper-Arid \\
\hline \multirow{3}{*}{ RGs } & Kendal $\tau$ & 0.517 & 0.55 & 0.5 & -0.450 \\
\hline & Sen's Slope & 4.682 & 4.924 & 5.506 & -3.804 \\
\hline & $p$-value & $0.009 * * *$ & $0.007^{* * *}$ & $0.003^{* * *}$ & $0.000^{* * *}$ \\
\hline \multirow{3}{*}{ RWALS } & Kendal $\tau$ & 0.517 & 0.533 & 0.483 & -0.450 \\
\hline & Sen's Slope & 4.384 & 4.739 & 4.682 & -3.719 \\
\hline & $p$-value & $0.010 * * *$ & $0.007^{* * *}$ & $0.003^{* * *}$ & $0.000^{* * *}$ \\
\hline \multirow{3}{*}{ WALS } & Kendal $\tau$ & 0.5 & 0.517 & 0.467 & -0.450 \\
\hline & Sen's Slope & 3.486 & 4.984 & 3.315 & -3.685 \\
\hline & $p$-value & $0.012 * * *$ & $0.010^{* * *}$ & $0.005^{* * *}$ & $0.005^{* * *}$ \\
\hline \multirow{3}{*}{ DCBA } & Kendal $\tau$ & 0.483 & 0.4 & 0.45 & -0.417 \\
\hline & Sen's Slope & 3.342 & 4.714 & 3.111 & -3.535 \\
\hline & $p$-value & $0.015^{* * *}$ & $0.024^{* * *}$ & $0.015^{* * *}$ & $0.009 * * *$ \\
\hline \multirow{3}{*}{ DBMA } & Kendal $\tau$ & 0.482 & 0.467 & 0.417 & -0.400 \\
\hline & Sen's Slope & 2.949 & 4.452 & 2.312 & -2.596 \\
\hline & $p$-value & $0.024 * *$ & $0.048^{* *}$ & $0.024^{* *}$ & $0.009^{* * *}$ \\
\hline \multirow{3}{*}{ IMERG } & Kendal $\tau$ & 0.383 & 0.383 & 0.383 & -0.333 \\
\hline & Sen's Slope & 2.61 & 4.122 & 2.247 & -1.344 \\
\hline & $p$-value & $0.024 * *$ & $0.059 *$ & $0.024^{* *}$ & $0.015^{* * *}$ \\
\hline \multirow{3}{*}{ TMPA } & Kendal $\tau$ & 0.383 & 0.367 & 0.35 & -0.333 \\
\hline & Sen's Slope & 2.404 & 3.693 & 2.011 & -3.359 \\
\hline & $p$-value & $0.028^{* *}$ & $0.059 *$ & $0.048^{*}$ & $0.019^{* *}$ \\
\hline \multirow{3}{*}{ PERSIANN-CDR } & Kendal $\tau$ & 0.317 & 0.3 & 0.3 & -0.300 \\
\hline & Sen's Slope & 2.481 & 3.328 & 1.993 & -2.165 \\
\hline & $p$-value & 0.050 * & 0.078 * & $0.059 *$ & $0.050 * *$ \\
\hline \multirow{3}{*}{ Era-Interim } & Kendal $\tau$ & 0.3 & 0.3 & 0.283 & -0.283 \\
\hline & Sen's Slope & 2.376 & 3.134 & 1.602 & -2.907 \\
\hline & $p$-value & 0.050 * & $0.078 *$ & $0.059 *$ & $0.038^{* *}$ \\
\hline
\end{tabular}

\section{Discussion}

\subsection{Possible Data Sources of Precipitation and Their Limitations}

Precipitation plays an important role in the management of water resources and assessment of drought. Therefore, reliable estimates of precipitation are of utmost importance for different hydrological applications and modeling [25]. RGs, the most reliable in situ precipitation sources, have several limitations, i.e., limited in number, non-uniform 
distribution, do not represent the local precipitation regime due to discontinued precipitation observation, several sources of errors, and even hard to get the data from their respective organizations, especially in developing countries. Based on these limitations, several studies have evaluated SPDs as an input precipitation source in monitoring drought. The individual SPDs also have several inevitable associated errors due to several factors, which are briefly discussed [18]. Therefore, the application of individual SPDs for drought monitoring is a major challenge, and a number of studies have reported poor performance of SPDs in drought assessment [16,17,59-62]. These studies have reported high dependencies of SPDs on local climate, topographic complexity, and the density of RGs for bias correction. Therefore, the current study tested all the possible sources of precipitation, including RGs, MSPDs, and SPDs to monitor meteorological drought across a data-scarce and developing country, Pakistan. The potentials of several input precipitation datasets have been thoroughly investigated, and their limitations across different climate regions are pointed out.

Previous studies demonstrated that MSPDs have significantly high potentials for various hydrological applications [57,58]. Therefore, based on the high performance of MSPDs, several researchers have focused on developing MSPDs across different regions around the globe. Very recently, Zheng et al. [48] developed MSPD using the double machine learning (DML) approach over China. They merged three near real-time SPDs, including IMERG, GSMaP (Global Satellite Mapping of Precipitation), and PERSIANN with SM2RIAN-ASCAT. Results reported better performance of DML-MSPD with a KGE score ranging from 0.67 to 0.71 . DML-MSPD also depicted higher CC (0.75-0.78), bias ratio (0.97-1.02), and variability ratio (0.83-0.90). Furthermore, DML-MSPD also depicted better performance in capturing precipitation with a threshold of $1 \mathrm{~mm} /$ day, as compared to standalone SPDs. Mastrantonas et al. [90] developed MSPD by merging five near real-time SPDs, including CMORPH, GSMaP, IMERG Early, IMERG Late, and PERSAINN SPDs using three techniques, i.e., Error Variance (EV), Inverse Error Variance Weighting (IEVW), and Simple Averaging (SA). Results showed that all SPDs have accurate precipitation estimates for lower intensity precipitation events, while they underestimated (more than $50 \%$ ) the typhoon-induced rainfall. However, merged datasets demonstrated higher accuracy during all temporal scales. Ma et al. [91] used the two-stage blending procedure to develop MSPD across the Tibetan Plateau using PERSIANN-CDR, TMPA 3B42V7, CMORPH, and IMERG V06. They also reported better performance of MSPD as compared with standalone SPDs. Overall, MSPDs are a better alternative to SPDs over topographically complex regions with different ranges of precipitation intensities.

DCBA-MSPD, DBMA-MSPD, WALS-MSPD, and RWALS-MSPD are developed and extensively evaluated over the complex topography and diverse climate of Pakistan. A previous study has shown that RWALS-MSPD is the best MSPD developed across Pakistan, followed by WALS and DCBA MSPDs [56]. RWALS-MSPD addresses the high magnitude of SPDs errors (across glacial and humid regions) on a regional scale by proposing different sets of SPDs evaluated using several statistical indices. The better performance of the above-mentioned MSPDs over Pakistan motivated us to assess their potentials in hydrology (meteorological drought monitoring). The current study demonstrates the superiority of MSPDs, especially RWALS-, WALS-, and DCBA-MSPDs, over SPDs (Figures 3 and 4) in drought assessment across the whole of Pakistan and on regional scales (Figures 7-9). Moreover, the performance of SPDs and MSPDs are also compared with RGs, and results show the superior performance of MSPDs (Tables 4-6). Furthermore, trend analyses performed using the MK test also depict the high performance of MSPDs after RGs (Tables 7-9).

\subsection{Spatio-Temporal Pattern of Drought Across Pakistan}

The intensity of drought across all Pakistan is ranging from mildly wet to moderate drought during different years in the study period (2000-2015). However, on a regional scale, the severity of drought is dependent on the climate, topography, and density of RGs. The glacial region has experienced mildly wet to moderate drought, the humid 
region showed very wet to mildly drought conditions, and the arid region is characterized with mildly wet (across elevated regions at the extreme west of the region) to moderate drought. The hyper-arid region receives minimal precipitation and thus is prone to severe drought. Therefore, moderate to severe drought conditions are observed across the hyper-arid region. Overall, the results showed that severe drought is observed in the years 2000-2003 while 2007, 2008, and 2012 are the most common drought years in all climate regions. Moreover, the magnitude of SPI indices is increasing from RGs to RWALS-MSPD toward the ERA-Interim. Most of the re-analysis datasets overestimate the precipitation, especially high precipitation events, in different regions around the world [92,93]. Most of the issues are due to difficulties in calculating clear-sky related estimates; i.e., ERA-Interim might underestimate the cloud fraction. Re-analysis datasets often predict clear-sky conditions, which in reality conditions are cloudy and vice versa [94]. However, the application and assessment of re-analysis datasets are varying from region to region around the globe. PERSIANN-CDR also demonstrated poor performance to assess drought over Pakistan. This might be associated with its poor performance in precipitation estimates confirmed by several studies $[41,69]$.

The potentials of MSPDs and SPDs are also evaluated across different climate regions in four seasons, i.e., pre-monsoon (AMJ), monsoon (JAS), post-monsoon (ON), and winter (DJFM). Year 2008 was selected based on the minimum precipitation during the year and data availability for all MSPDs and SPDs. The precipitation trend during each season across different climate regions is depicted in drought analyses.

The spatial distribution pattern of drought is consistent with the erratic nature of precipitation and its distribution during different seasons across different climate regions. Mild to moderate wet conditions are depicted during the monsoon season characterized by heavy and intense precipitation (Figure 3). On the other hand, the winter season shows mild to severe drought across different climate regions of Pakistan (Figure 4). The regionalscale drought assessment also showed consistent results based on precipitation distribution. During the monsoon season, the glacial region depicted moderate to very wet conditions, the humid region presented moderate wet to very wet conditions, and the arid and hyperarid regions showed mildly wet to moderate drought conditions. However, mild drought in the glacial region, mild to moderate drought in the humid region, mild to moderate drought in the arid region, and moderate to severe drought in the hyper-arid region have been observed in winter seasons.

RGs and MSPDs have closer drought estimates, while SPDs (especially PERSIANNCDR and ERA-Interim) exaggerated the drought conditions. Previous studies have shown that SPDs have considerably overestimated the precipitation across glacial and humid regions while underestimating it in arid and hyper-arid regions. The seasonal assessment demonstrated that SPDs overestimated and underestimated precipitation during the monsoon and winter seasons across Pakistan. The same characteristics of overestimation and underestimation are propagated to SPIs calculation, i.e., very wet to moderate drought conditions (SPDs depicted more drought severity as compared to RGs and MSPDs) have been observed across glacial/humid and arid/hyper-arid regions during the representative year.

\subsection{Comparison of Drought (SPI) with Different Time Scales}

The potentials of MSPDs and SPDs are assessed at a regional scale using SPI-1, SPI-3, and SPI-12. The analyses show that MSPDs had captured the drought severity and magnitude of SPIs with high accuracies. However, the SPDs (more specifically PERSIANN-CDR and ERA-Interim) performed relatively poorer and have relatively poor precision to capture the drought trend/severity. High fluctuations are observed in the SPIs estimated with SPDs and more specifically for PERSIANN-CDR and ERA-Interim. Moreover, the analyses (Figures 7-9) presented that the magnitude of SPIs increases from RGs to MSPDs and SPDs. Finally, the temporal-scale analyses of drought showed that years 2000 to 2002 are the major drought years across all climate regions. 
The comparison among SPIs (from SPI-1 to SPI-3 and SPI-12) revealed high fluctuations in drought severity (magnitude) being observed in SPI-1 and SPI-3, which is declining toward the SPI-12. The regional-scale evaluation also showed that the drought pattern is not well captured by SPDs across the hyper-arid region except for SPI-12. On the other hand, MSPDs developed by the relative and adaptive weights of SPDs have captured the trend and magnitude of drought with relatively high precision.

The performance of MSPDs and SPDs is compared with RGs using three statistical indices, i.e., MAD, RMSD, and MAPD. The results (Tables 4-6) depicted a high magnitude of errors for SPI-1 and SPI-3, which are decreasing toward the SPI-12. The reason for the improved performance of SPI-12 is that the 12-month moving average of precipitation aggregates are used for SPI-12, which stabilizes the peak of drought and wet months and thus results in stable performance.

\subsection{Potentials and Limitations of MSPDs}

The performance assessment of MSPDs (SPDs) across all climate regions of Pakistan has revealed the relatively poor performance of MSPDs/SPDs across glacial and humid regions while showing improved performance in arid and hyper-arid regions. The poor performance of SPDs/MSPDs in glacial and humid regions is due to several factors; i.e., infrared (IR) and passive microwave (PMW) sensors are mostly used to estimate precipitation [95], where IR retrieves the information from the top of the cloud using minimum temperature, and PMW sensors acquire the information about precipitation rather than cloud. Glacial regions have relatively warmer clouds and thus restrain the capability of IR to distinguish between precipitation and no precipitation clouds $[96,97]$. Moreover, more precipitation without much ice aloft is produced by orographic clouds over the mountainous regions (glacial and humid), which is not considered by the PMW algorithm and thus underestimates the precipitation [95]. Moreover, a relatively coarser spatial resolution of PMW sensors as compared with IR supplemented with high vegetation cover in the mountains also causes uncertainties in precipitation estimates. Furthermore, signal attenuation due to heavy precipitation in the humid region, errors due to retrieval algorithms, ignoring the elevation and sub-cloud evaporation, challenges in the processing of microwave and IR data, the calibration procedure of retrieval algorithm, topographic complexity, and external errors associated with RGs contribute to the lower performance of SPDs and in turn MSPDs across glacial and humid regions [89,98-100]. The developed MSPDs over Pakistan did not consider the near-real-time SPDs as merging members, which may hinder the applicability of MSPDs in the assessment and forecasting of different hydrological applications [48]. Furthermore, before the development of MSPDs and their applications in hydrological modeling, it is better to remove/minimize the biases in precipitation estimates from SPDs. However, it is an arduous task to detect and reduce different bias components.

RGs are subjected to several types of external errors, even after the quality control step, followed by PMD and WAPDA after WMO-N code. The observed precipitation records from RGs might still have errors from wind splashing, wetting, evaporation losses, splashing effects, and underestimated trace precipitation [101]. Moreover, the RGs are nonuniformly (dense distribution in the humid region while scarce distribution in other climate regions; see Figure 1). The errors associated with RGs might have propagated to MSPDs because RGs are considered as a reference. Furthermore, as mentioned by Zhang et al., [48], only geographical and topographical auto-correlation and covariates have been considered in the frameworks of developed MSPDs. Other factors such as soil moisture from SPDs and cloud properties are not considered $[47,102]$. The reason for the high performance of MSPDs is the advantage of merging different SPDs, which are reducing uncertainties and have a higher potential for hydrological applications [57]. RWALS-MSPD has reduced the high magnitude of errors (as can be seen in WALS, DCBA, and DBMA MSPDs) across glacial and humid regions. The relatively highest performance of RWALS-MSPD lies in the fact that it is developed by merging the conventional SPDs and SM2RAIN-based SPDs. Top-down SPDs overestimate the precipitation across glacial and humid regions, while SM2RAIN- 
based SPDs have the tendency to underestimate the precipitation. Therefore, the merging of SM2RAIN-based products with other conventional SPDs abates the amplified errors in glacial and humid regions and thus resulted in relatively high performance in comparison with other MSPDs. In addition, region-wise, the selection of appropriate SPDs resulted in better precipitation estimates compared to the selection of the same set of SPDs for each climate region. MSPDs and SPDs depicted high MAD, RMSD, and MAPD values (poor performance) across glacial and humid regions. SPDs demonstrated dependency on elevation and topography and have a high magnitude of errors across these regions. These errors are propagated to MSPDs, which shows maximum error in glacial and humid regions in monitoring drought.

\section{Conclusions}

The current study evaluated the performance of satellite precipitation datasets (SPDs) and merged satellite precipitation datasets (MSPDs) against the RGs to monitor drought over Pakistan during 2000-2015. SPDs include IMERG, TMPA, PERSIANN-CDR, and ERAInterim, while the set of MSPDs is comprised of RWALS, WALS, DCBA, and DBMA. Several standardized precipitation indices, including SPI-1, SPI-3, and SPI-12, are used to monitor the drought and potential of SPDs and MSPDs in drought assessment across Pakistan and on a regional scale. The Mann-Kendall (MK) test is also used to assess the trend of drought across all climate regions of Pakistan using all SPI indices. Based on the comprehensive evaluation of SPDs and MSPDs, the main findings of the current study are summarized below.

(1) Relatively wet conditions are observed during the monsoon season of 2008 (a selected representative drought year) across different climate regions of Pakistan. Overall, the conditions in the monsoon region are varying from mildly wet to moderate wet with SPI-3 values ranging from 0.38 for RGs to 1.16 for ERA-Interim. On a regional scale, glacial and humid regions have experienced mildly wet to moderately wet conditions with average regional values of 0.68 and 0.64 for RGs. The arid region has mildly drought to mildly wet conditions with an average SPI-3 value of 0.16 . However, both wet and drought conditions are observed across the hyper-arid region.

(2) The winter season of 2008 depicted mild to moderate drought across different climate regions of Pakistan. The RGs and MSPDs, except for the DCBA and DBMA (only at a few RGs), show mild to moderate drought, which is amplified to severe drought for individual SPDs. The average SPI-3 values are ranging from -0.84 for RGs to -1.78 for ERA-Interim across all Pakistan. The results of monsoon and winter seasons of 2008 indicate that MSPDs are superior to SPDs in depicting the spatial pattern of meteorological drought; especially, the RWALS-MSPD performs the best.

(3) Regional-scale analyses revealed that the performance of SPDs and MSPDs are increasing from SPI-1 to SPI-12, i.e., SPI-12 of SPDs/MSPDs have relatively high performance in comparison with RGs. The reason behind better estimates of SPI-12 is the relatively long time period for cumulative precipitation.

(4) The regional analyses based on SPI-1, SPI-3, and SPI-12 confirmed the high performance of all MSPDs as compared with SPDs. MSPDs accurately captured the drought intensity and its variation trend, while SPDs failed to do so. RWALS-MSPD is the best MSPDs among all datasets having MAPD values less than 10\% (representing high accurate estimation) across all climate regions. The performance of other MSPDs is ranging from highly accurate (MAPD < 10\%) estimations to good estimation (10-20\% MAPD). On the other hand, the SPDs have a relatively weak performance with MAPD values of $>20 \%$ (depicting reasonable estimation).

(5) The results of trend analyses using the MK test revealed the high performance of RWALS- and WALS-MSPDs evaluated using Kendal's $\tau$, Sen's Slope, and $p$-values. SPI-3 shows a relatively low significance level, which can be observed from Kendal's $\tau$, Sen's Slope, and $p$-values, as compared with and SPI-12. Moreover, SPDs and MSPDs 
are depicting an increasing (positive) trend over glacial, humid, and arid regions and a decreasing (negative) trend across the hyper-arid region.

Overall, the detailed evaluation of MSPDs and SPDs compared with RGs across Pakistan revealed a high performance of all MSPDs. The performance of RWALS-MSPD is significantly closer to RGs in drought estimation; however, the performance is decreasing from RWALS to WALS, DCBA, and DBMA MSPDs. The results showed that MSPDs combine the advantages of merging SPDs and have the potential to be used for drought assessment in data-scarce regions or poorly gauged catchments. Several studies, along with the current study, reported poor performance of SPDs to monitor drought.

Author Contributions: The research was conceived by K.U.R. and S.S.; conceptualization, K.U.R. and S.S.; methodology, K.U.R. and M.Z.; software, K.U.R. and M.Z.; validation, K.U.R.; data curation, K.U.R.; writing—original draft preparation, K.U.R.; writing-review and editing, K.U.R., S.S., and M.Z.; supervision, S.S., funding acquisition, S.S. All authors have read and agreed to the published version of the manuscript.

Funding: This research was financially supported by the National Natural Science Foundation of China (Grant numbers 51779119 and 51839006).

Data Availability Statement: Restrictions apply to the availability of these data. Data were obtained from Pakistan Meteorology Department (PMD) and Water and Power Development Authority (WAPDA). The data can be purchased from PMD and WAPDA, available at http:/ / www.pmd.gov. pk/cdpc/cost.htm and http:/ / www.wapda.gov.pk/ (accessed on: 5 April 2021).

Acknowledgments: The authors extend their gratitude to the Water and Power Development Authority (WAPDA), Pakistan Meteorological Department (PMD) for providing the rain gauge precipitation data, and thankful to SPDs developers. The authors are thankful to anonymous reviewers for their constructive comments that helped us to greatly improve the quality of manuscript.

Conflicts of Interest: The authors declare no conflict of interest.

\section{References}

1. Zarch, M.A.A.; Sivakumar, B.; Sharma, A. Droughts in a warming climate: A global assessment of Standardized precipitation index (SPI) and Reconnaissance drought index (RDI). J. Hydrol. 2015, 526, 183-195. [CrossRef]

2. Sivakumar, B. Water crisis: From conflict to cooperation-An overview. Hydrol. Sci. J. 2011, 56, 531-552. [CrossRef]

3. Haroon, M.A.; Zhang, J.; Yao, F. Drought monitoring and performance evaluation of MODIS-based drought severity index (DSI) over Pakistan. Nat. Hazards 2016, 84, 1349-1366. [CrossRef]

4. Igbawua, T.; Zhang, J.; Yao, F.; Zhang, D. Assessment of moisture budget over West Africa using MERRA-2's aerological model and satellite data. Clim. Dyn. 2019, 52, 83-106. [CrossRef]

5. Yao, N.; Li, Y.; Lei, T.; Peng, L. Drought evolution, severity and trends in mainland China over 1961-2013. Sci. Total Environ. 2018, 616, 73-89. [CrossRef]

6. Liu, Q.; Zhang, S.; Zhang, H.; Bai, Y.; Zhang, J. Monitoring drought using composite drought indices based on remote sensing. Sci. Total Environ. 2020, 711, 134585. [CrossRef]

7. Kalisa, W.; Zhang, J.; Igbawua, T.; Ujoh, F.; Ebohon, O.J.; Namugize, J.N.; Yao, F. Spatio-temporal analysis of drought and return periods over the East African region using Standardized Precipitation Index from 1920 to 2016. Agric. Water Manag. 2020, 237, 106195. [CrossRef]

8. Khan, N.; Sachindra, D.; Shahid, S.; Ahmed, K.; Shiru, M.S.; Nawaz, N. Prediction of droughts over Pakistan using machine learning algorithms. Adv. Water Resour. 2020, 139, 103562. [CrossRef]

9. Xu, L.; Chen, N.; Zhang, X.; Chen, Z. An evaluation of statistical, NMME and hybrid models for drought prediction in China. J. Hydrol. 2018, 566, 235-249. [CrossRef]

10. Gocic, M.; Trajkovic, S. Spatiotemporal characteristics of drought in Serbia. J. Hydrol. 2014, 510, 110-123. [CrossRef]

11. Adnan, S.; Ullah, K.; Shuanglin, L.; Gao, S.; Khan, A.H.; Mahmood, R. Comparison of various drought indices to monitor drought status in Pakistan. Clim. Dyn. 2018, 51, 1885-1899. [CrossRef]

12. Society, A.M. Meteorological drought-policy statement. Bull. Am. Meteorol. Soc. 1997, 78, 847-849.

13. Shahid, M.; Rahman, K.U. Identifying the Annual and Seasonal Trends of Hydrological and Climatic Variables in the Indus Basin Pakistan. Asia Pac. J. Atmos. Sci. 2020, 57, 191-205. [CrossRef]

14. Ahmed, K.; Shahid, S.; bin Harun, S.; Wang, X.-J. Characterization of seasonal droughts in Balochistan Province, Pakistan. Stoch. Environ. Res. Risk Assess. 2016, 30, 747-762. [CrossRef]

15. Lin, A.; Wang, X.L. An algorithm for blending multiple satellite precipitation estimates with in situ precipitation measurements in Canada. J. Geophys. Res. Atmos. 2011, 116, D21111. [CrossRef] 
16. Lai, C.; Zhong, R.; Wang, Z.; Wu, X.; Chen, X.; Wang, P.; Lian, Y. Monitoring hydrological drought using long-term satellite-based precipitation data. Sci. Total Environ. 2019, 649, 1198-1208. [CrossRef] [PubMed]

17. Zhong, R.; Chen, X.; Lai, C.; Wang, Z.; Lian, Y.; Yu, H.; Wu, X. Drought monitoring utility of satellite-based precipitation products across mainland China. J. Hydrol. 2019, 568, 343-359. [CrossRef]

18. Rahman, K.U.; Shang, S.; Shahid, M.; Wen, Y.; Khan, Z. Application of a Dynamic Clustered Bayesian Model Averaging (DCBA) Algorithm for Merging Multisatellite Precipitation Products over Pakistan. J. Hydrometeorol. 2020, 21, 17-37. [CrossRef]

19. Bai, X.; Wu, X.; Wang, P. Blending long-term satellite-based precipitation data with gauge observations for drought monitoring: Considering effects of different gauge densities. J. Hydrol. 2019, 577, 124007. [CrossRef]

20. Dai, A. Increasing drought under global warming in observations and models. Nat. Clim. Chang. 2013, 3, 52-58. [CrossRef]

21. IPCC. The Physical Science Basis of Climate Change; Cambridge University Press: Cambridge, UK, 2007.

22. Wang, Z.; Zhong, R.; Lai, C.; Zeng, Z.; Lian, Y.; Bai, X. Climate change enhances the severity and variability of drought in the Pearl River Basin in South China in the 21st century. Agric. For. Meteorol. 2018, 249, 149-162. [CrossRef]

23. Piao, S.; Ciais, P.; Huang, Y.; Shen, Z.; Peng, S.; Li, J.; Zhou, L.; Liu, H.; Ma, Y.; Ding, Y. The impacts of climate change on water resources and agriculture in China. Nature 2010, 467, 43-51. [CrossRef]

24. Lai, C.; Li, J.; Wang, Z.; Wu, X.; Zeng, Z.; Chen, X.; Lian, Y.; Yu, H.; Wang, P.; Bai, X. Drought-induced reduction in net primary productivity across mainland China from 1982 to 2015. Remote Sens. 2018, 10, 1433. [CrossRef]

25. Rahman, K.U.; Shang, S.; Shahid, M.; Wen, Y. Performance assessment of SM2RAIN-CCI and SM2RAIN-ASCAT precipitation products over Pakistan. Remote Sens. 2019, 11, 2040. [CrossRef]

26. Baez-Villanueva, O.M.; Zambrano-Bigiarini, M.; Ribbe, L.; Nauditt, A.; Giraldo-Osorio, J.D.; Thinh, N.X. Temporal and spatial evaluation of satellite rainfall estimates over different regions in Latin-America. Atmos. Res. 2018, 213, 34-50. [CrossRef]

27. Jin, B.; Wu, Y.; Miao, B.; Wang, X.L.; Guo, P. Bayesian spatiotemporal modeling for blending in situ observations with satellite precipitation estimates. J. Geophys. Res. Atmos. 2014, 119, 1806-1819. [CrossRef]

28. Wang, Z.; Zhong, R.; Lai, C.; Chen, J. Evaluation of the GPM IMERG satellite-based precipitation products and the hydrological utility. Atmos. Res. 2017, 196, 151-163. [CrossRef]

29. Sheffield, J.; Wood, E.F.; Roderick, M.L. Little change in global drought over the past 60 years. Nature 2012, 491, 435-438. [CrossRef] [PubMed]

30. Trenberth, K.E.; Dai, A.; Van Der Schrier, G.; Jones, P.D.; Barichivich, J.; Briffa, K.R.; Sheffield, J. Global warming and changes in drought. Nat. Clim. Chang. 2014, 4, 17-22. [CrossRef]

31. Sun, R.; Yuan, H.; Liu, X.; Jiang, X. Evaluation of the latest satellite-gauge precipitation products and their hydrologic applications over the Huaihe River basin. J. Hydrol. 2016, 536, 302-319. [CrossRef]

32. Huffman, G.J.; Bolvin, D.T.; Nelkin, E.J.; Wolff, D.B.; Adler, R.F.; Gu, G.; Hong, Y.; Bowman, K.P.; Stocker, E.F. The TRMM multisatellite precipitation analysis (TMPA): Quasi-global, multiyear, combined-sensor precipitation estimates at fine scales. J. Hydrometeorol. 2007, 8, 38-55. [CrossRef]

33. Mahmoud, M.T.; Al-Zahrani, M.A.; Sharif, H.O. Assessment of global precipitation measurement satellite products over Saudi Arabia. J. Hydrol. 2018, 559, 1-12. [CrossRef]

34. Tang, G.; Wen, Y.; Gao, J.; Long, D.; Ma, Y.; Wan, W.; Hong, Y. Similarities and differences between three coexisting spaceborne radars in global rainfall and snowfall estimation. Water Resour. Res. 2017, 53, 3835-3853. [CrossRef]

35. Hou, A.Y.; Kakar, R.K.; Neeck, S.; Azarbarzin, A.A.; Kummerow, C.D.; Kojima, M.; Oki, R.; Nakamura, K.; Iguchi, T. The global precipitation measurement mission. Bull. Am. Meteorol. Soc. 2014, 95, 701-722. [CrossRef]

36. Hong, Y.; Hsu, K.-L.; Sorooshian, S.; Gao, X. Precipitation estimation from remotely sensed imagery using an artificial neural network cloud classification system. J. Appl. Meteorol. 2004, 43, 1834-1853. [CrossRef]

37. Ashouri, H.; Hsu, K.-L.; Sorooshian, S.; Braithwaite, D.K.; Knapp, K.R.; Cecil, L.D.; Nelson, B.R.; Prat, O.P. PERSIANN-CDR: Daily precipitation climate data record from multisatellite observations for hydrological and climate studies. Bull. Am. Meteorol. Soc. 2015, 96, 69-83. [CrossRef]

38. Joyce, R.J.; Janowiak, J.E.; Arkin, P.A.; Xie, P. CMORPH: A method that produces global precipitation estimates from passive microwave and infrared data at high spatial and temporal resolution. J. Hydrometeorol. 2004, 5, 487-503. [CrossRef]

39. Dee, D.P.; Uppala, S.M.; Simmons, A.; Berrisford, P.; Poli, P.; Kobayashi, S.; Andrae, U.; Balmaseda, M.; Balsamo, G.; Bauer, D.P. The ERA-Interim reanalysis: Configuration and performance of the data assimilation system. Q. J. R. Meteorol. Soc. 2011, 137, 553-597. [CrossRef]

40. Ma, Y.; Hong, Y.; Chen, Y.; Yang, Y.; Tang, G.; Yao, Y.; Long, D.; Li, C.; Han, Z.; Liu, R. Performance of optimally merged multisatellite precipitation products using the dynamic Bayesian model averaging scheme over the Tibetan Plateau. J. Geophys. Res. Atmos. 2018, 123, 814-834. [CrossRef]

41. Rahman, K.U.; Shang, S.; Shahid, M.; Li, J. Developing an ensemble precipitation algorithm from satellite products and its topographical and seasonal evaluations over Pakistan. Remote Sens. 2018, 10, 1835. [CrossRef]

42. Tang, G.; Ma, Y.; Long, D.; Zhong, L.; Hong, Y. Evaluation of GPM Day-1 IMERG and TMPA Version-7 legacy products over Mainland China at multiple spatiotemporal scales. J. Hydrol. 2016, 533, 152-167. [CrossRef]

43. Wang, L.; Li, X.; Ma, C.; Bai, Y. Improving the prediction accuracy of monthly streamflow using a data-driven model based on a double-processing strategy. J. Hydrol. 2019, 573, 733-745. [CrossRef] 
44. Lin, P.; Pan, M.; Allen, G.H.; de Frasson, R.P.; Zeng, Z.; Yamazaki, D.; Wood, E.F. Global estimates of reach-Level bankfull river width leveraging big data geospatial analysis. Geophys. Res. Lett. 2020, 47, e2019GL086405. [CrossRef]

45. Derin, Y.; Bhuiyan, M.A.E.; Anagnostou, E.; Kalogiros, J.; Anagnostou, M.N. Modeling Level 2 Passive Microwave Precipitation Retrieval Error Over Complex Terrain Using a Nonparametric Statistical Technique. IEEE Trans. Geosci. Remote Sens. 2021, in press. [CrossRef]

46. Bhuiyan, M.A.E.; Yang, F.; Biswas, N.K.; Rahat, S.H.; Neelam, T.J. Machine learning-based error modeling to improve GPM IMERG precipitation product over the brahmaputra river basin. Forecasting 2020, 2, 14. [CrossRef]

47. Kumar, A.; Ramsankaran, R.; Brocca, L.; Munoz-Arriola, F. A Machine Learning Approach for Improving Near-Real-Time Satellite-Based Rainfall Estimates by Integrating Soil Moisture. Remote Sens. 2019, 11, 2221. [CrossRef]

48. Zhang, L.; Li, X.; Zheng, D.; Zhang, K.; Ma, Q.; Zhao, Y.; Ge, Y. Merging multiple satellite-based precipitation products and gauge observations using a novel double machine learning approach. J. Hydrol. 2021, 594, 125969. [CrossRef]

49. Bhuiyan, M.A.E.; Nikolopoulos, E.I.; Anagnostou, E.N.; Quintana-Seguí, P.; Barella-Ortiz, A. A nonparametric statistical technique for combining global precipitation datasets: Development and hydrological evaluation over the Iberian Peninsula. Hydrol. Earth Syst. Sci. 2018, 22, 1371-1389. [CrossRef]

50. Baez-Villanueva, O.M.; Zambrano-Bigiarini, M.; Beck, H.E.; McNamara, I.; Ribbe, L.; Nauditt, A.; Birkel, C.; Verbist, K.; GiraldoOsorio, J.D.; Thinh, N.X. RF-MEP: A novel Random Forest method for merging gridded precipitation products and ground-based measurements. Remote Sens. Environ. 2020, 239, 111606. [CrossRef]

51. Wehbe, Y.; Temimi, M.; Adler, R.F. Enhancing precipitation estimates through the fusion of weather radar, satellite retrievals, and surface parameters. Remote Sens. 2020, 12, 1342. [CrossRef]

52. Wu, H.; Yang, Q.; Liu, J.; Wang, G. A spatiotemporal deep fusion model for merging satellite and gauge precipitation in China. J. Hydrol. 2020, 584, 124664. [CrossRef]

53. Yin, J.; Guo, S.; Gu, L.; Zeng, Z.; Liu, D.; Chen, J.; Shen, Y.; Xu, C.-Y. Blending multi-satellite, atmospheric reanalysis and gauge precipitation products to facilitate hydrological modelling. J. Hydrol. 2021, 593, 125878. [CrossRef]

54. Rahman, K.U.; Shang, S.; Shahid, M.; Wen, Y. An Appraisal of Dynamic Bayesian Model Averaging-based Merged Multi-Satellite Precipitation Datasets Over Complex Topography and the Diverse Climate of Pakistan. Remote Sens. 2020, 12, 10. [CrossRef]

55. Rahman, K.U.; Shang, S.; Shahid, M.; Wen, Y.; Khan, A.J. Development of a novel weighted average least squares-based ensemble multi-satellite precipitation dataset and its comprehensive evaluation over Pakistan. Atmos. Res. 2020, 246, 105133. [CrossRef]

56. Rahman, K.U.; Shang, S.; Rahman, K.U.; Shang, S. A Regional Blended Precipitation Dataset over Pakistan Based on Regional Selection of Blending Satellite Precipitation Datasets and the Dynamic Weighted Average Least Squares Algorithm. Remote Sens. 2020, 12, 4009. [CrossRef]

57. Rahman, K.U.; Shang, S.; Shahid, M.; Wen, Y. Hydrological evaluation of merged satellite precipitation datasets for streamflow simulation using SWAT: A case study of Potohar Plateau, Pakistan. J. Hydrol. 2020, 587, 125040. [CrossRef]

58. Ma, Y.; Yang, Y.; Han, Z.; Tang, G.; Maguire, L.; Chu, Z.; Hong, Y. Comprehensive evaluation of ensemble multi-satellite precipitation dataset using the dynamic bayesian model averaging scheme over the Tibetan Plateau. J. Hydrol. 2018, 556, 634-644. [CrossRef]

59. Yong, B.; Ren, L.L.; Hong, Y.; Wang, J.H.; Gourley, J.J.; Jiang, S.H.; Chen, X.; Wang, W. Hydrologic evaluation of Multisatellite Precipitation Analysis standard precipitation products in basins beyond its inclined latitude band: A case study in Laohahe basin, China. Water Resour. Res. 2010, 46, W07542. [CrossRef]

60. Sahoo, A.K.; Sheffield, J.; Pan, M.; Wood, E.F. Evaluation of the tropical rainfall measuring mission multi-satellite precipitation analysis (TMPA) for assessment of large-scale meteorological drought. Remote Sens. Environ. 2015, 159, 181-193. [CrossRef]

61. Duan, Z.; Liu, J.; Tuo, Y.; Chiogna, G.; Disse, M. Evaluation of eight high spatial resolution gridded precipitation products in Adige Basin (Italy) at multiple temporal and spatial scales. Sci. Total Environ. 2016, 573, 1536-1553. [CrossRef]

62. Katsanos, D.; Retalis, A.; Michaelides, S. Validation of a high-resolution precipitation database (CHIRPS) over Cyprus for a 30-year period. Atmos. Res. 2016, 169, 459-464. [CrossRef]

63. Zambrano, F.; Wardlow, B.; Tadesse, T.; Lillo-Saavedra, M.; Lagos, O. Evaluating satellite-derived long-term historical precipitation datasets for drought monitoring in Chile. Atmos. Res. 2017, 186, 26-42. [CrossRef]

64. Gao, F.; Zhang, Y.; Chen, Q.; Wang, P.; Yang, H.; Yao, Y.; Cai, W. Comparison of two long-term and high-resolution satellite precipitation datasets in Xinjiang, China. Atmos. Res. 2018, 212, 150-157. [CrossRef]

65. Guo, H.; Bao, A.; Liu, T.; Chen, S.; Ndayisaba, F. Evaluation of PERSIANN-CDR for meteorological drought monitoring over China. Remote Sens. 2016, 8, 379. [CrossRef]

66. Hanif, M.; Khan, A.H.; Adnan, S. Latitudinal precipitation characteristics and trends in Pakistan. J. Hydrol. 2013, 492, 266-272. [CrossRef]

67. Asmat, U.; Athar, H. Run-based multi-model interannual variability assessment of precipitation and temperature over Pakistan using two IPCC AR4-based AOGCMs. Theor. Appl. Climatol. 2017, 127, 1-16. [CrossRef]

68. Balkhair, K.S.; Rahman, K.U. Sustainable and economical small-scale and low-head hydropower generation: A promising alternative potential solution for energy generation at local and regional scale. Appl. Energy 2017, 188, 378-391. [CrossRef]

69. Hussain, Y.; Satgé, F.; Hussain, M.B.; Martinez-Carvajal, H.; Bonnet, M.-P.; Cárdenas-Soto, M.; Roig, H.L.; Akhter, G. Performance of CMORPH, TMPA, and PERSIANN rainfall datasets over plain, mountainous, and glacial regions of Pakistan. Theor. Appl. Climatol. 2018, 131, 1119-1132. [CrossRef] 
70. Iqbal, M.F.; Athar, H. Validation of satellite based precipitation over diverse topography of Pakistan. Atmos. Res. 2018, 201, 247-260. [CrossRef]

71. Khan, N.; Shahid, S.; bin Ismail, T.; Wang, X.-J. Spatial distribution of unidirectional trends in temperature and temperature extremes in Pakistan. Theor. Appl. Climatol. 2019, 136, 899-913. [CrossRef]

72. Kumar, K.K.; Rajagopalan, B.; Cane, M.A. On the weakening relationship between the Indian monsoon and ENSO. Science 1999, 284, 2156-2159. [CrossRef] [PubMed]

73. Hunt, K.M.; Turner, A.G.; Shaffrey, L.C. The evolution, seasonality and impacts of western disturbances. Q. J. R. Meteorol. Soc. 2018, 144, 278-290. [CrossRef]

74. Ahmed, K.; Shahid, S.; Nawaz, N. Impacts of climate variability and change on seasonal drought characteristics of Pakistan. Atmos. Res. 2018, 214, 364-374. [CrossRef]

75. Dimri, A.; Niyogi, D.; Barros, A.; Ridley, J.; Mohanty, U.; Yasunari, T.; Sikka, D. Western disturbances: A review. Rev. Geophys. 2015, 53, 225-246. [CrossRef]

76. Huffman, G.J.; Bolvin, D.T.; Braithwaite, D.; Hsu, K.; Joyce, R.; Kidd, C.; Nelkin, E.J.; Sorooshian, S.; Tan, J.; Xie, P. NASA Global Precipitation Measurement (GPM). In Integrated Multi-Satellite Retrievals for GPM (IMERG), Algorithm Theoretical Basis Document (ATBD) Version 5.2; NASA/GSFC: Greenbelt, MD, USA, 2018.

77. Brocca, L.; Ciabatta, L.; Massari, C.; Moramarco, T.; Hahn, S.; Hasenauer, S.; Kidd, R.; Dorigo, W.; Wagner, W.; Levizzani, V. Soil as a natural rain gauge: Estimating global rainfall from satellite soil moisture data. J. Geophys. Res. Atmos. 2014, 119, 5128-5141. [CrossRef]

78. Brocca, L.; Filippucci, P.; Hahn, S.; Ciabatta, L.; Massari, C.; Camici, S.; Schüller, L.; Bojkov, B.; Wagner, W. SM2RAIN-ASCAT (2007-2018): Global daily satellite rainfall from ASCAT soil moisture. Earth Syst. Sci. Data 2019, 11, 1583-1601. [CrossRef]

79. Brocca, L.; Moramarco, T.; Melone, F.; Wagner, W. A new method for rainfall estimation through soil moisture observations Geophys. Res. Lett. 2013, 40, 853-858. [CrossRef]

80. Ciabatta, L.; Massari, C.; Brocca, L.; Gruber, A.; Reimer, C.; Hahn, S.; Paulik, C.; Dorigo, W.; Kidd, R.; Wagner, W. SM2RAIN-CCI: A new global long-term rainfall data set derived from ESA CCI soil moisture. Earth Syst. Sci. Data 2018, 10, 267. [CrossRef]

81. Farahmand, A.; AghaKouchak, A. A generalized framework for deriving nonparametric standardized drought indicators. Adv. Water Resour. 2015, 76, 140-145. [CrossRef]

82. McKee, T.B.; Doesken, N.J.; Kleist, J. The relationship of drought frequency and duration to time scales. In Proceedings of the 8th Conference on Applied Climatology, Anaheim, CA, USA, 17-22 January 1993; pp. 179-183.

83. Mann, H.B. Nonparametric tests against trend. Econom. J. Econom. Soc. 1945, 13, 245-259. [CrossRef]

84. Kendall, M.G. Rank Correlation Methods; Charles Griffin and Co. Ltd.: London, UK, 1948.

85. Fu, G.; Chen, S.; Liu, C.; Shepard, D. Hydro-climatic trends of the Yellow River basin for the last 50 years. Clim. Chang. 2004, 65, 149-178. [CrossRef]

86. Sen, P.K. Estimates of the regression coefficient based on Kendall's tau. J. Am. Stat. Assoc. 1968, 63, 1379-1389. [CrossRef]

87. West, K.D. Forecast evaluation. In Handbook of Economic Forecasting; Elsevier: Amsterdam, the Netherlands, 2006; Volume 1, pp. 99-134.

88. Lewis, C.D. Industrial and Business Forecasting Methods: A Practical Guide to Exponential Smoothing and Curve Fitting; ButterworthHeinemann: Oxford, UK, 1982.

89. Tapiador, F.; Navarro, A.; Levizzani, V.; García-Ortega, E.; Huffman, G.; Kidd, C.; Kucera, P.; Kummerow, C.; Masunaga, H.; Petersen, W. Global precipitation measurements for validating climate models. Atmos. Res. 2017, 197, 1-20. [CrossRef]

90. Mastrantonas, N.; Bhattacharya, B.; Shibuo, Y.; Rasmy, M.; Espinoza-Dávalos, G.; Solomatine, D. Evaluating the benefits of merging near-real-time satellite precipitation products: A case study in the Kinu basin region, Japan. J. Hydrometeorol. 2019, 20, 1213-1233. [CrossRef]

91. Ma, Y.; Sun, X.; Chen, H.; Hong, Y.; Zhang, Y. A two-stage blending approach for merging multiple satellite precipitation estimates and rain gauge observations: An experiment in the northeastern Tibetan Plateau. Hydrol. Earth Syst. Sci. 2021, 25, 359-374. [CrossRef]

92. Belo-Pereira, M.; Dutra, E.; Viterbo, P. Evaluation of global precipitation data sets over the Iberian Peninsula. J. Geophys. Res. 2011, 116, D20101. [CrossRef]

93. Thiemig, V.; Rojas, R.; Zambrano-Bigiarini, M.; Levizzani, V.; De Roo, A. Validation of satellite-based precipitation products over sparsely gauged African river basins. J. Hydrometeorol. 2012, 13, 1760-1783. [CrossRef]

94. Naud, C.M.; Booth, J.F.; Del Genio, A.D. Evaluation of ERA-Interim and MERRA cloudiness in the Southern Ocean. J. Clim. 2014, 27, 2109-2124. [CrossRef]

95. Dinku, T.; Connor, S.J.; Ceccato, P. Comparison of CMORPH and TRMM-3B42 over mountainous regions of Africa and South America. In Satellite Rainfall Applications for Surface Hydrology; Springer: Dordrecht, the Netherlands, 2010; pp. $193-204$.

96. Hong, Y.; Gochis, D.; Cheng, J.T.; Hsu, K.L.; Sorooshian, S. Evaluation of PERSIANN-CCS rainfall measurement using the NAME event rain gauge network. J. Hydrometeorol. 2007, 8, 469-482. [CrossRef]

97. Bitew, M.M.; Gebremichael, M. Evaluation through independent measurements: Complex terrain and humid tropical region in Ethiopia. In Satellite Rainfall Applications for Surface Hydrology; Springer: Dordrecht, the Netherlands, 2010; pp. $205-214$.

98. Villarini, G.; Krajewski, W.F. Review of the different sources of uncertainty in single polarization radar-based estimates of rainfall. Surv. Geophys. 2010, 31, 107-129. [CrossRef] 
99. AghaKouchak, A.; Nasrollahi, N.; Habib, E. Accounting for uncertainties of the TRMM satellite estimates. Remote Sens. 2009, 1, 606-619. [CrossRef]

100. Scheel, M.L.M.; Rohrer, M.; Huggel, C.; Santos Villar, D.; Silvestre, E.; Huffman, G.J. Evaluation of TRMM Multi-satellite Precipitation Analysis (TMPA) performance in the Central Andes region and its dependency on spatial and temporal resolution. Hydrol. Earth Syst. Sci. 2011, 15, 2649-2663. [CrossRef]

101. Zhang, L.; Li, X.; Cao, Y.; Nan, Z.; Wang, W.; Ge, Y.; Yu, W. Evaluation and integration of the top-down and bottom-up satellite precipitation products over mainland China. J. Hydrol. 2020, 581, 124456. [CrossRef]

102. Sharifi, E.; Saghafian, B.; Steinacker, R. Downscaling satellite precipitation estimates with multiple linear regression, artificial neural networks, and spline interpolation techniques. J. Geophys. Res. Atmos. 2019, 124, 789-805. [CrossRef] 